\title{
The reactivation of somatosensory cortex and behavioral recovery after sensory loss in mature primates
}

\author{
Hui-Xin Qi *, Jon H. Kaas and Jamie L. Reed \\ Department of Psychology, Vanderbilt University, Nashville, TN, USA
}

\section{Edited by:}

Mikhail Lebedev, Duke University, USA

\section{Reviewed by:}

Preston E. Garraghty, Indiana University, USA

Ioan Opris, Wake Forest University, USA

\section{*Correspondence:}

Hui-Xin Qi, Department of

Psychology, Vanderbilt University,

11121 st Ave. S., Nashville,

TN 37240, USA

e-mail: huixin.qi@vanderbilt.edu
In our experiments, we removed a major source of activation of somatosensory cortex in mature monkeys by unilaterally sectioning the sensory afferents in the dorsal columns of the spinal cord at a high cervical level. At this level, the ascending branches of tactile afferents from the hand are cut, while other branches of these afferents remain intact to terminate on neurons in the dorsal horn of the spinal cord. Immediately after such a lesion, the monkeys seem relatively unimpaired in locomotion and often use the forelimb, but further inspection reveals that they prefer to use the unaffected hand in reaching for food. In addition, systematic testing indicates that they make more errors in retrieving pieces of food, and start using visual inspection of the rotated hand to confirm the success of the grasping of the food. Such difficulties are not surprising as a complete dorsal column lesion totally deactivates the contralateral hand representation in primary somatosensory cortex (area $3 b$ ). However, hand use rapidly improves over the first post-lesion weeks, and much of the hand representational territory in contralateral area $3 \mathrm{~b}$ is reactivated by inputs from the hand in roughly a normal somatotopic pattern. Quantitative measures of single neuron response properties reveal that reactivated neurons respond to tactile stimulation on the hand with high firing rates and only slightly longer latencies. We conclude that preserved dorsal column afferents after nearly complete lesions contribute to the reactivation of cortex and the recovery of the behavior, but second-order sensory pathways in the spinal cord may also play an important role. Our microelectrode recordings indicate that these preserved first-order, and second-order pathways are initially weak and largely ineffective in activating cortex, but they are potentiated during the recovery process. Therapies that would promote this potentiation could usefully enhance recovery after spinal cord injury.

Keywords: area 3b, cuneate nucleus, monkey, plasticity, spinal cord, ventroposterior nucleus, somatosensory system

\section{INTRODUCTION}

The last 30 years of intensive research has led to a greatly improved understanding of how the somatosensory system of mature primates and other mammals responds to sensory loss, as reviewed by others (Buonomano and Merzenich, 1998; Jones, 2000; Wall et al., 2002; Kaas et al., 2008; Darian-Smith, 2009; Xerri, 2012). The types of sensory loss that have been experimentally studied have varied, ranging from the loss of peripheral nerves, especially the median nerve to the glabrous skin of the hand (Merzenich et al., 1983a,b; Silva et al., 1996; Florence et al., 1998; Xu and Wall, 1999), the sectioning of dorsal roots of peripheral nerve afferents as they enter the spinal cord (Pons et al., 1991; Jones and Pons, 1998; Darian-Smith and Brown, 2000; Darian-Smith, 2004; Darian-Smith and Ciferri, 2005, 2006), the loss of a digit or part of forelimb (Kelahan and Doetsch, 1984; Crockett et al., 1993; Florence and Kaas, 1995; Sengelaub et al., 1997; Florence et al., 1998; Li et al., 2013), the section of peripheral nerve afferents as they travel in the dorsal columns of spinal cord (Jain et al., 1997, 1998, 2000, 2008; Weng et al., 2003; Graziano and Jones, 2009; Qi et al., 2011a), or spinal cord injury in rodents (Ghosh et al., 2009; Aguilar et al., 2010; Humanes-Valera et al., 2013). All these types of sensory loss deactivate topographically matched parts of the somatosensory system, including parts of the ipsilateral dorsal column-trigeminal complex in lower brainstem and the contralateral ventroposterior nucleus (VP) of the thalamus, and the primary (area $3 \mathrm{~b}$ ) and other areas (1 and 2) of contralateral somatosensory cortex. These extensive deactivations were expected from the somatotopic organization and hierarchical arrangement of these processing stations.

What was not expected, at least by most investigators, was that over various amounts of time, the deactivated parts of the somatosensory system became responsive to tactile stimulation again, based on the somatosensory inputs that remained. Some changes in the receptive fields of neurons in the somatosensory system were apparent as soon as they could be measured after sensory loss (Wall, 1977; Calford and Tweedale, 1988; Faggin et al., 1997; Xu and Wall, 1997, 1999; Krupa et al., 1999), and these immediate changes could be attributed to the removal of the excitatory drive on central inhibitory neurons that normally constrain the receptive fields of relay neurons by keeping some of the excitatory inputs subthreshold. Other reactivations with greater changes in the receptive field locations of central neurons occurred over hours to weeks, such as the reactivation of cortical neurons previously activated from the glabrous skin of 
the hand by touch on the back of the hand after sectioning of the median nerve to the glabrous skin of digits 1-3 (Merzenich et al., 1983a,b). Such rapid reactivations may largely result from the potentiation of previously existing subthreshold inputs, especially in the cuneate nucleus representing the hand in the lower brainstem, by homeostatic mechanisms (Garraghty et al., 1991; Turrigiano, 1999; Wellman et al., 2002), and possibly by new axon growth over short distances (Darian-Smith and Gilbert, 1994; Jain et al., 2000; Darian-Smith, 2004; Hickmott and Steen, 2005; Cheetham et al., 2008; Yamahachi et al., 2009; Marik et al., 2010, 2014). Other reactivations that follow the loss or denervation of the forelimb, including invasion by inputs from the face (Pons et al., 1991; Jain et al., 1997, 2000; Wu and Kaas, 1999; Florence et al., 2000), may take many months to emerge (Jain et al., 1997), and depend on longer distances of new axon growth at subcortical and cortical levels (Florence et al., 1998; Jain et al., 2000). Cortical reorganization after limb amputations in humans can be found in several studies (Flor et al., 1995, 1998; Elbert et al., 1997; Davis et al., 1998; Lotze et al., 1999; Brugger et al., 2000; Moore et al., 2000; Curt et al., 2002). Thus, reactivations commonly occur in humans and other primates after a total loss of a subset of peripheral nerve inputs. In part, the reactivations after injury involve activity-dependent homeostatic cellular mechanisms, but also require the growth of new connections for greater changes in somatotopy. Because of the need for longer axon growth, greater changes in somatotopy take a longer time to emerge. Finally, somatotopic reorganization in cortex may usefully compensate for some of the sensory loss, but extensive reorganizations appear to lead to persisting mislocalization of sensory stimuli, such that the activation of hand cortex by inputs from the face leads to sensation felt on a phantom hand (Ramachandran, 1993; Davis et al., 1998; Ramachandran and Rogers-Ramachandran, 2000). Hence, somatosensory reactivations that restore much of normal somatotopy may be the most useful in restoring lost functions after sensory system damage. For example, highly somatotopic reactivations may occur when a loss of peripheral nerve afferents from any given region of skin is incomplete, as the subsequent potentiation of remaining weak or subthreshold inputs allows aspects of normal somatotopic order in central representations to be restored, at least partially. This may happen after selective sections of the dorsal roots of peripheral nerves as they enter the spinal cord (Darian-Smith and Brown, 2000; Darian-Smith and Ciferri, 2005, 2006), as similar inputs from a region of skin may enter over several dorsal roots (Welker, 1973), including roots left intact. In a similar manner, sectioning of peripheral nerve afferents as they ascend in the dorsal column of the spinal cord may leave a scattering of afferents that can restore some of the normal somatotopy of the deactivated somatosensory cortex (Jain et al., 1997). Alternatively, the information provided by cutting dorsal column afferents may not be totally lost, because these afferents branch as they enter the spinal cord. One branch ascends in the dorsal columns and the other terminates on the dorsal horn neurons in the spinal cord. As this sensory information is preserved, a more useful somatotopic reactivation of cortex may emerge based on the connections of the spinal cord neurons. The remainder of this review mainly focuses on the consequences of dorsal column lesions of the spinal cord in primates, including characteristics of natural recoveries and potential for augmented recoveries, but it is not intended to be a comprehensive literature review of other types of injuries and recovery mechanisms.

\section{DORSAL COLUMN LESIONS IN PRIMATES}

Dorsal column lesions in monkeys and other primates provide a number of advantages in studies of central nervous system reorganization after sensory loss. Most importantly, the loss is selective for the afferents that convey low-threshold, rapidly conducting tactile inputs from the slowly adapting and rapidly adapting receptors in the skin, while less rapidly conducting afferents for pain, temperature, and crude touch are left intact, as these afferents bypass the dorsal columns (Kaas, 2012). In addition, proprioceptive information from receptors located in muscles and joints travels in peripheral nerve afferents that ascend lateral to the dorsal column afferents in the spinal cord, where they are damaged only if the dorsal column lesion includes the fibers of the lateral spinal cord. Furthermore, the peripheral nerve afferents that contribute to the dorsal columns branch, such that one branch terminates in the dorsal horn of the spinal cord while another branch ascends in the dorsal columns to terminate in the brainstem. Although one branch is cut by the dorsal column lesion, the other branch may still function in the dorsal horn, where the afferents continue to contribute to spinal cord reflexes and other spinal cord functions, and possibly to ascending sensory pathways that compensate for dorsal column lesions. Studies of the effects of dorsal column lesions in rats have produced useful information (for reviews, see Kaas et al., 2008; Onifer et al., 2011); however, unlike the separation between the sensory and motor pathways in primates, corticospinal (motor) projections course in the dorsal columns in rodents (Hicks and D'Amato, 1975; D'Amato and Hicks, 1978; Vahlsing and Feringa, 1980; Paxino and Watson, 2007). Therefore, dorsal column lesions in rodents involve a direct motor loss in addition to the sensory loss. Thus, the use of dorsal column lesions in primates has the advantages of producing a rather specific loss of tactile capacities, while leaving other functions intact. Importantly, these specific lesions in primates are followed by unexpected levels of behavioral recovery (see below). While the lesions do not mimic the typical types of injury that occur in most cases of spinal cord injury in humans, where damage may be extensive and somewhat non-specific, the lesions can be made with precision and consistency so that useful results can be obtained from a few subjects. Consistent results from similar lesions allow therapeutic procedures to be evaluated. Thus, experimental results from monkeys have the potential of providing information that can usefully guide the interpretations and predictions of consequences of spinal cord damage in humans, and hopefully guide the development of therapeutic procedures.

Our experiments typically involve a unilateral lesion of the dorsal columns at a C4-C5 level of the spinal cord (Figure 1). This removes the primary afferent tactile inputs to the cuneate nucleus from one hand, while leaving the inputs from the other hand intact. All inputs to the dorsal horn neurons of the spinal cord are preserved, as are the primary proprioceptive afferents in the lateral spinal cord pathway. Neurons in the elongated cuneate nucleus project to the hand and forelimb subnucleus of 


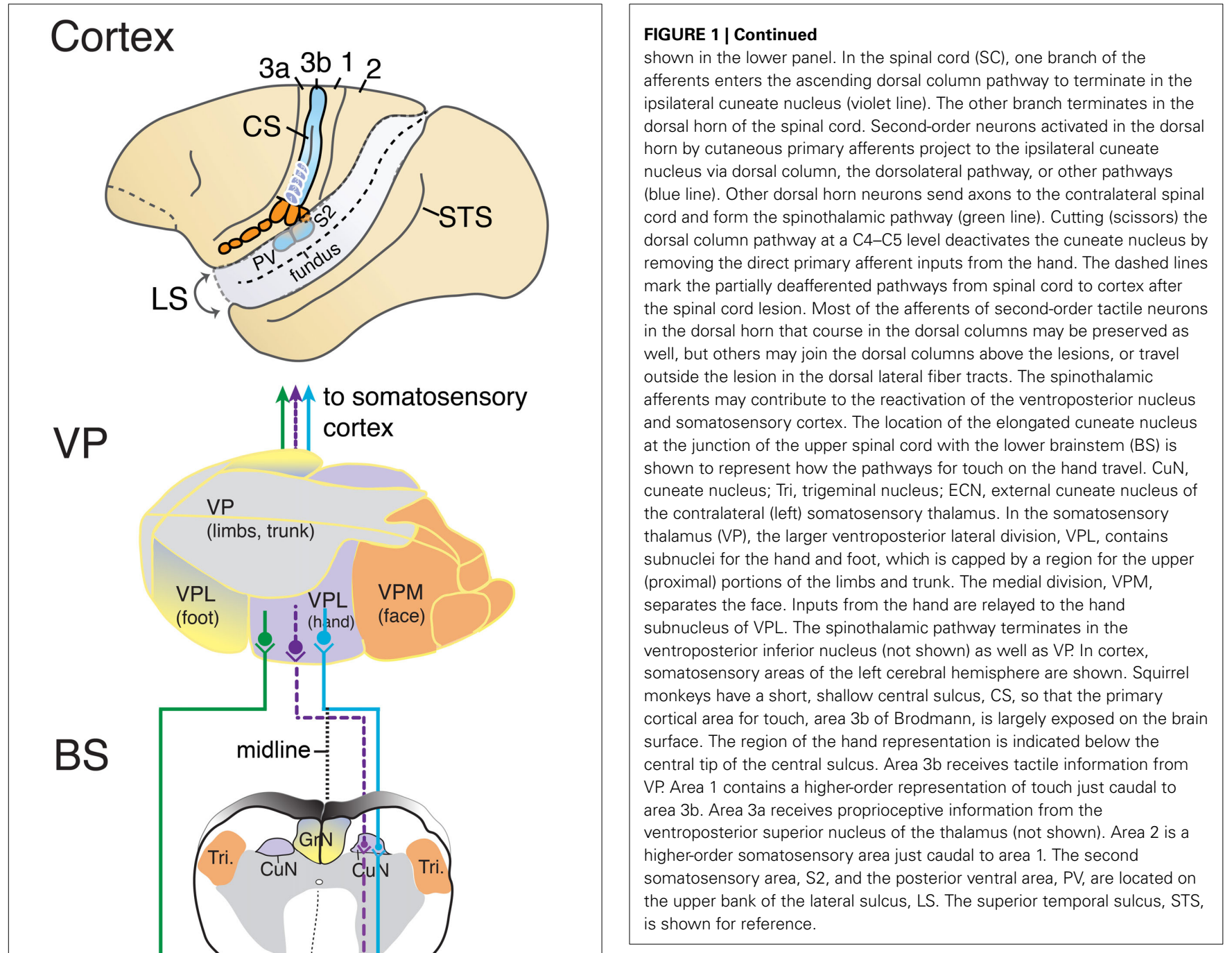

the ventroposterior nucleus (VP) of the contralateral thalamus. VP is commonly divided into a lateral "nucleus" (VPL) representing the contralateral upper and lower body, and a medial "nucleus" (VPM) representing the contralateral face and both the contralateral and ipsilateral tongue and teeth (Kaas et al., 2006). VP projects to primary somatosensory cortex, area $3 \mathrm{~b}$, in a somatotopic pattern, so that the hand subnucleus projects to the hand representation in area $3 \mathrm{~b}$ just medial to that of the face and lateral to that of the arm and trunk. The VP inputs activate area $3 \mathrm{~b}$ neurons, while VP provides subthreshold projections to area 1 (e.g., Nelson and Kaas, 1981; Garraghty et al., 1990a), which has a somatotopic organization that parallels and mirrors that in area 3b (Kaas et al., 1979).

In our experiments, we typically determine the effects of dorsal column lesions by recording from the hand subdivision of contralateral area $3 \mathrm{~b}$ in squirrel monkeys or owl monkeys with microelectrodes. Squirrel monkeys have only a short, shallow central sulcus, and owl monkeys have only a short central dimple. For both of these primates, the representations of the hand in area $3 \mathrm{~b}$ and in adjoining areas $3 \mathrm{a}$ and 1 are exposed on the surface of the brain. This exposure of the cortical areas allows activity patterns to be mapped in detail with densely spaced 
microelectrode penetrations. Microelectrode mapping can also be done at thalamic and brainstem levels, but not under visual guidance. Therefore, the somatotopy of these subcortical representations is both harder to determine in detail, and harder to illustrate compared to the two-dimensional cortical maps. In addition, reorganized area $3 \mathrm{~b}$ maps reflect both subcortical alterations and those that originate in area $3 \mathrm{~b}$. Thus, area $3 \mathrm{~b}$ is a key location for investigation in most experiments. We and others have also studied area $3 \mathrm{~b}$ reorganization in macaque monkey (Pons et al., 1991; Florence and Kaas, 1995; Florence et al., 1998; Darian-Smith and Brown, 2000; Jain et al., 2008), where area 3b is hidden on the caudal bank of a deep central fissure, as in humans. These more difficult studies are important because macaques are used as a more common model for human brain organization, as macaque brains have some features of the somatosensory system that more closely resemble those of humans.

Neurons in the hand portion of area $3 b$ typically have small excitatory receptive fields, mostly located on the glabrous skin of the hand, especially on the distal phalanges of digits, and they are often confined to part of a single phalange of a digit or pad of the palm. Nearby neurons have similar receptive fields, and a systematic partial map of the hand representation in area $3 \mathrm{~b}$ can be reconstructed from a dense array of microelectrode recordings across the hand region by outlining all electrode penetration sites with receptive fields centered on any digit phalanges or pad of the palm, or part of the body (Merzenich et al., 1978; Nelson et al., 1980; Sur et al., 1982; Krubitzer and Kaas, 1990). Such maps are extremely consistent in somatotopy across individuals, and they conform to the orderly arrangement of projections from VP to area 3b (Jones et al., 1982; Kaas et al., 1984; Cusick and Gould, 1990; Qi et al., 2011b; Liao et al., 2013). In addition, narrow cellpoor septa separate the representations of digits in area $3 \mathrm{~b}$ so that digit territories are histologically visible (Qi and Kaas, 2004). The most apparent of these cortical septa separates the representation of digit 1, the thumb, from that of the face; and this septum serves as a highly useful landmark when recording sites are related to cortical histology (Jain et al., 1998, 2001).

\section{THE REACTIVATION AND REORGANIZATION OF SOMATOSENSORY CORTEX AFTER DORSAL COLUMN LESIONS}

As the primary somatosensory cortical area for tactile stimuli, area $3 \mathrm{~b}$ has been the most studied area after dorsal column injury. Most of the results have been obtained from multiple microelectrode recordings where receptive fields for cortical neurons have been defined by stimulating the skin with hand-held probes. Traditionally, near-threshold skin indentations are used to define the "minimal excitatory receptive field" (Merzenich et al., 1983a). In reactivated regions of cortex deprived of their normal sources of activation, neuron responses are subjectively classified as good or excellent, meaning that the neuron responses to light touch closely resemble those in normal cortex, or as poor, or nonresponsive. Recordings in deprived cortex immediately after a dorsal column lesion reveal that this cortex is totally unresponsive to light tactile stimuli. Thus, no neuronal spikes are evoked in deprived cortex, while neurons in un-deprived cortex, such as face cortex, respond normally. After a dorsal column lesion at a high cervical level above $\mathrm{C} 4$, the hand cortex in area $3 \mathrm{~b}$ is completely deprived and unresponsive. Over a period of 3-4 weeks, much of the deprived hand cortex starts to respond to touch on the hand, with a distorted but crudely normal somatotopy. Thus, neurons responsive to touch on digit 1 (thumb) are in cortex lateral to those for digit 2 , and digits $1-5$ are represented in a lateral to medial order. However, this pattern is often disrupted by displaced islands of neurons that represent the same digit, patches of cortex that remain unresponsive, and neurons with discontinuous receptive fields that represent more than one location on the hand. Such results have been reported in a number of studies, including those from owl monkeys, squirrel monkeys, marmosets, and macaque monkeys (Jain et al., 1997, 1998, 2008; Qi et al., 2011a; Bowes et al., 2012, 2013).

Studies of the reactivation process in monkeys with dorsal column lesion using imaging methods, such as fMRI, optical imaging, and radiographic imaging, have been limited but informative (Tommerdahl et al., 1996; Chen et al., 2012; Dutta et al., 2013; Yang et al., under revision). As an example, results from one squirrel monkey from Chen et al. (2012) are shown in Figure 2. Before a dorsal column lesion, tactile stimulation of each of the five digits resulted in a focus of activity in the hand region of area $3 \mathrm{~b}$, with foci for digits $1-5$ in the expected lateral to medial order (Figure 2A. In this anesthetized monkey, responses in area 1 were not reliably obtained. Four weeks after a dorsal column lesion at the C4-C5 level, area 3b was responsive to touch on the digits, and the somatotopic order of foci activated from each digit was roughly in the normal order, but distorted from the normal pattern (Figure 2B). After 8 weeks, the cortex was more responsive, and the somatotopic pattern appeared more normal (Figure 2C). When the final somatotopic pattern from fMRI was compared to an optical imaging pattern and a microelectrode map in the same monkey, there was good agreement between the activation patterns from the three methods, but optical imaging produced a more detailed map than the fMRI imaging, and greatest detail was provided by the microelectrode maps. Although the fMRI mapping provides less sensitive somatotopic detail than the microelectrode recordings or the optical imaging, fMRI allows the same cortex to be imaged multiple times non-invasively. Over an eight-week or even longer period of recovery, there was no evidence that the deprived hand cortex was reactivated by any other part of the body, including the face. However, after longer periods of 6-8 months to years, face inputs from the region of the chin often activate parts of the hand cortex (Jain et al., 1997).

When the dorsal column lesion is incomplete, perhaps as an unintended result, or because the lesion was intentionally placed at a lower C5-C6 level in order to preserve some inputs from digit 1 and a few from digit 2, then these preserved inputs come to represent larger than normal territories in area $3 b$ after 5-8 weeks of recovery with sensorimotor training and testing. However, much of the activation is in the normal territories for those digits. Somatotopic organization of reactivated cortex after recovery is likely dependent on the level and extent of the lesion, as indicated by studies using single microelectrodes to map the cortex (Qi et al., 2011a; Chen et al., 2012) and using multi-electrode arrays implanted in cortex (Qi et al., 2014). For example, receptive field mapping of neurons recorded with a 100-electrode array 

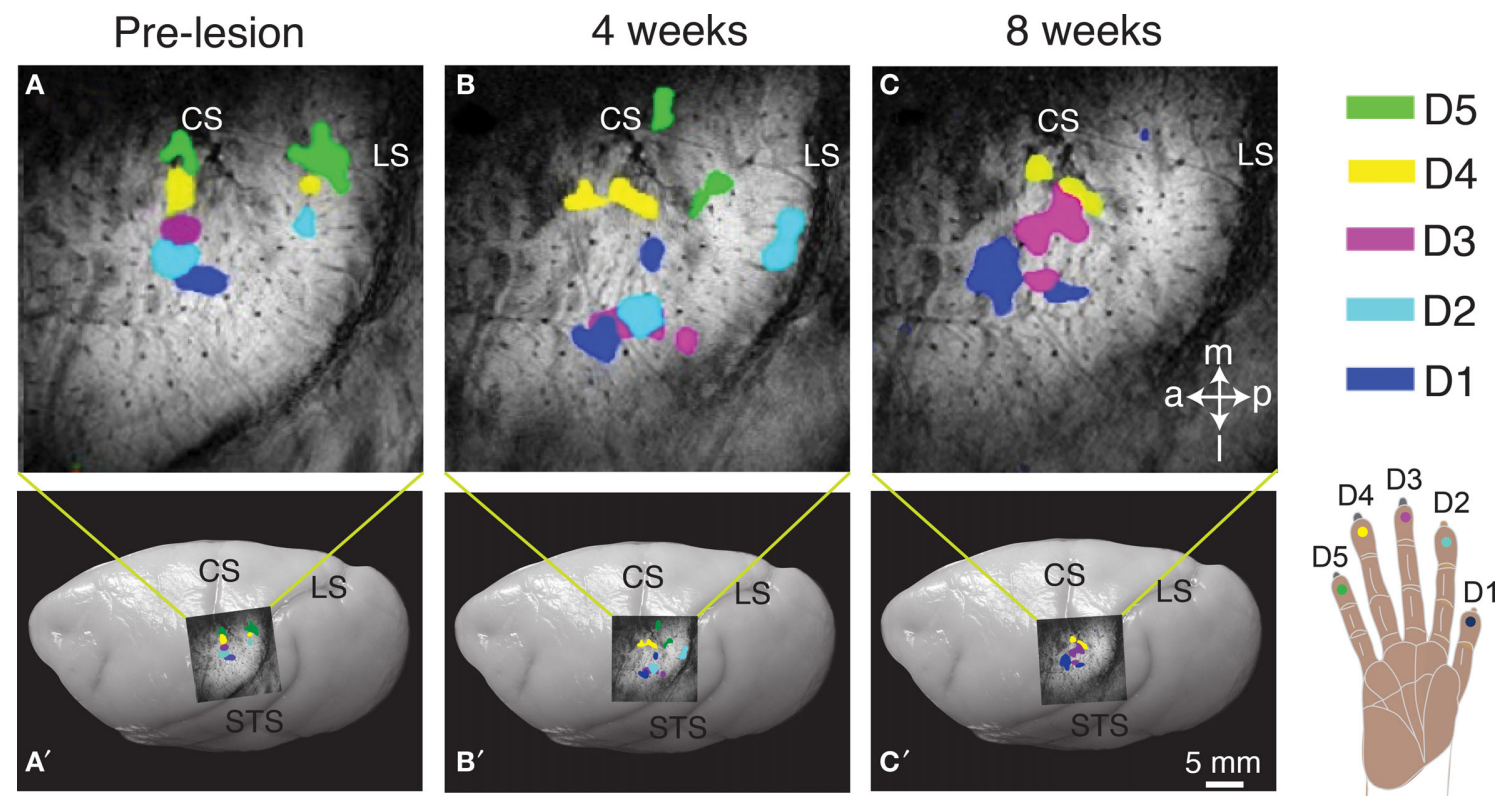

FIGURE 2 | Longitudinal mapping of $f M R I$ activation to vibrotactile stimulation on digits 1-5 pre-lesion $(A)$ and after 4-weeks $(B)$ and 8-weeks (C) post-lesion following unilateral dorsal column section in a squirrel monkey (SM-O). Activation foci from trial blocks of stimulation on individual digits were superimposed for the composite images (A-C). The location of the top panel on the brain is shown for each panel below. Dots on the hand schematic (lower right) are color-coded to represent the activation in cortex when that digit location was stimulated $(\mathbf{A}-\mathbf{C})$. Superimposed images of the $\mathrm{fMRI}$ activation on photograph of a squirrel monkey brain indicates the approximate location of the region of interest $\left(\mathbf{A}^{\prime}-\mathbf{C}^{\prime}\right)$. Abbreviations: a, anterior; CS, central sulcus; D1-5, digits 1-5; I, lateral; LS, lateral sulcus; m, medial; $p$, posterior; STS, superior temporal sulcus. Adapted from Chen et al. (2012). in area $3 b$ in a squirrel monkey showed that somatotopic organization in reactivated cortex was largely normal after behavioral recovery from a dorsal column lesion at the C6 level (compare Figures 3B,C). However, the cortical territories occupied by spared inputs for digits 1 and 2 encroached into regions deprived of input by the C6 lesion (digits 3-5). This monkey received sensorimotor training and testing for use of the impaired hand over the course of 6 weeks prior to recording with the array, and it is unknown what effect this behavioral intervention may have had on the cortical reactivation beyond what would have occurred spontaneously. In this case, preserved inputs activated their normal locations in cortex, but also came to activate larger than normal territories.

Finally, the reactivation of area $3 b$ hand cortex should result in the reactivation of the hand territories of other cortical areas that depend on area $3 \mathrm{~b}$ for activation, such as areas $1, \mathrm{~S} 2$, and PV, as reported previously (Pons et al., 1987; Burton et al., 1990; Garraghty et al., 1990b). Indeed, the area 1 representation of touch is restored in a somatotopic pattern that generally parallels that in area $3 \mathrm{~b}$, but it is less precise in detailed somatotopy, and the neuronal responses tend to be weaker in the reactivated regions (Merzenich et al., 1983a; Jain et al., 2008; Qi et al., 2011a). Responses to tactile stimuli also return to areas 3 a and 2 (Garraghty et al., 1990a; Bowes et al., 2013) and the hand region of areas S2 and PV (Pons et al., 1987, 1992; Burton et al., 1990; Garraghty et al., 1990b; Tandon et al., 2009; Wang et al., 2013; Yang et al., under revision). Areas 3 a and 2 receive proprioceptive input from the ventroposterior superior nucleus of the thalamus
(Kaas, 2012), so neurons in these areas may remain responsive to hand manipulation after dorsal column lesions that spare the proprioceptive axons in the lateral spinal cord. As all these areas recover responsiveness to tactile stimuli and provide direct and indirect inputs to motor and premotor cortex (Krubitzer and Kaas, 1990; Stepniewska et al., 1993; Disbrow et al., 2003; Fang et al., 2005; Qi et al., 2010; Kambi et al., 2011; see Wise et al., 1997 for review), considerable sensory guidance of motor behavior is restored.

\section{THE RESPONSE PROPERTIES OF REACTIVATED NEURONS IN AREA 3b}

Reactivated cortical neurons may have disorganized excitatory receptive fields, or larger than normal receptive fields, but these responses to light touch on the hand appear to range from subjectively normal amplitude to weak responses (Qi et al., 2014). Over recovery periods longer than $4-8$ weeks, more neurons likely become capable of stronger responses. Quantifying response properties beyond receptive field organization is a growing focus of study in the somatosensory system (Doetsch et al., 1996; Wang et al., 2013; Qi et al., 2014), but some support for these studies comes from studies of reactivated neurons in primary visual cortex after retinal lesions (Chino et al., 1995, 2001; Darian-Smith and Gilbert, 1995). Our quantitative studies of the response properties of reactivated cortical neurons after dorsal column lesions have been limited (Wang et al., 2013; Qi et al., 2014), but there is already evidence that reactivated neurons have responses to tactile stimuli (indentation of the skin with an electromechanical 


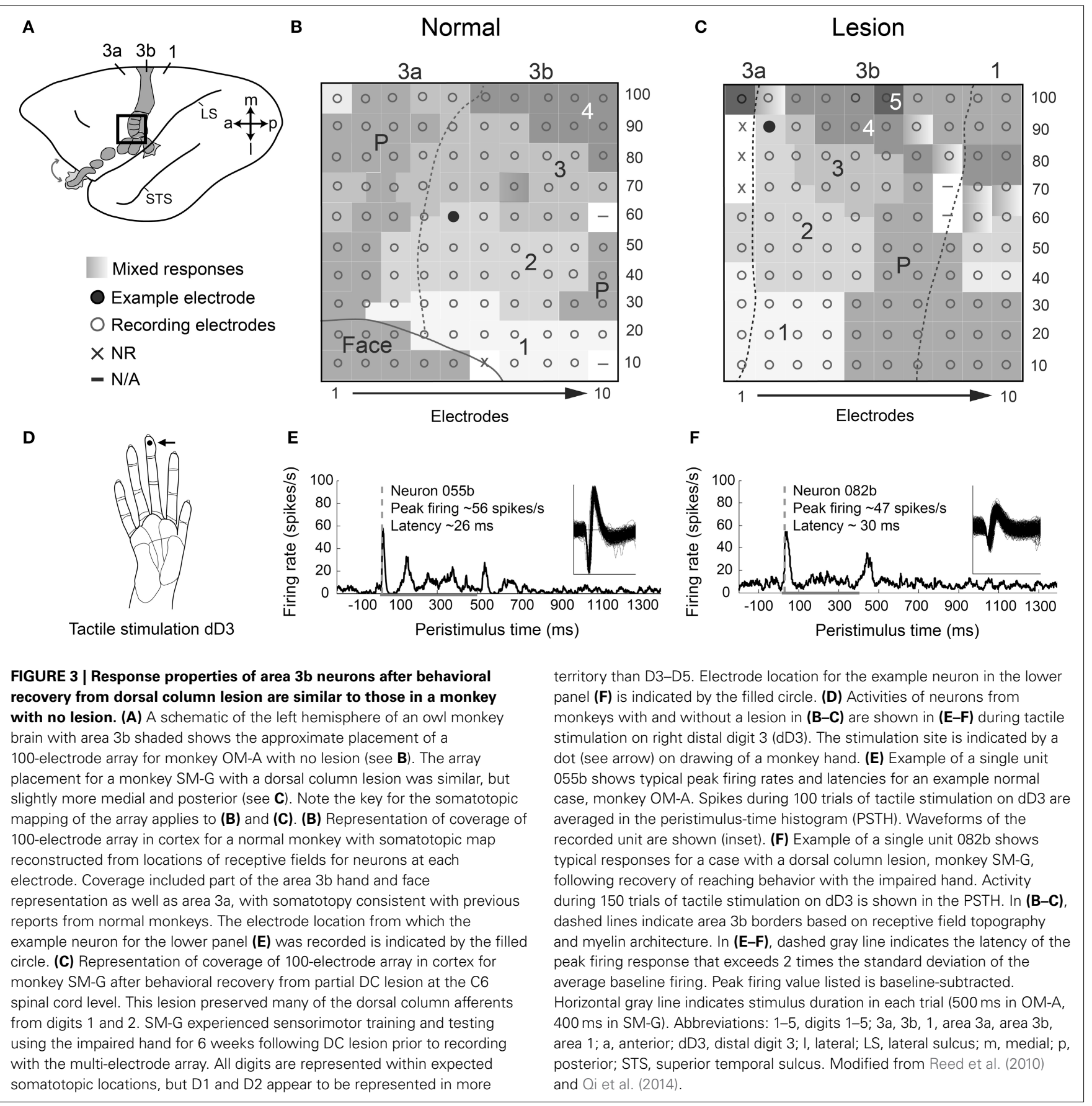

probe) that are in the normal or near-normal range, as indicated by examples of cortical activity (Figure 3) from an intact monkey (Reed et al., 2010) and a monkey 6 weeks after mid-cervical dorsal column lesion (Qi et al., 2014).

Qi et al. (2014) found that fewer neurons in area $3 b$ responded to tactile stimulation on the hand in monkeys after sensory loss followed by behavioral training compared to normal monkeys. However, peak firing rates of responsive neurons were similar in monkeys with and without lesions. An example neuron from a normal monkey (Figure 3E) maintained low levels of spontaneous firing and increased firing to about 56 spikes/s in response to the onset of a $500 \mathrm{~ms}$ depression of the skin on distal digit 3. This example showed some increased firing during the sustained indentation of the stimulus and a response to the removal of the stimulus from the skin. Such "off responses" are common in normal animals (Sur et al., 1984; Pei et al., 2009). The neuron's response with some maintained discharge during the duration of skin indentation is common in area $3 b$ neurons, as these neurons can show mixtures of properties reflecting both rapidlyadapting and slowly-adapting afferents (Sur et al., 1984; Pei et al., 2009). The example neuron in the reactivated cortex after nearly complete dorsal column lesion (Figure 3F) responded to both 
stimulus onset and removal, while maintaining some firing during the sustained skin indentation on distal digit 3. Notably, the neuron in reactivated cortex had somewhat lower peak firing rates during tactile stimulation at about 47 spikes/s, but still greater than the median response rates reported previously (about 18 spikes/s) and seemingly close to rates expected normally (Reed et al., 2010; Qi et al., 2014). In 3 monkeys with dorsal column lesions and after hand use in a reaching task recovered to normal levels, response latencies of neurons in reactivated area $3 \mathrm{~b}$ to skin indentation were similar to normal or slightly longer than normal, averaging about $31 \mathrm{~ms}$ [Reed et al., 2012 (abstract)]. Using similar recording methods and data analysis, Reed et al. (2010) found that response latencies of area $3 b$ neurons in normal monkeys averaged about $21 \mathrm{~ms}$. The example of neuronal activity in Figure 3 shows a neuron in a lesioned monkey with a response latency to skin indentation that was slightly longer than the latency of a normal neuron (compare Figure 3E to Figure 3F). Similar response rates with slightly longer latencies than normal may suggest that some sensory input reaches area $3 \mathrm{~b}$ after dorsal column lesions through alternative pathways that require additional synapses to reach the target. More study is needed, but the reactivated neurons clearly have response properties that could usefully guide behavior.

\section{THE EFFECTS OF DORSAL COLUMN LESION ON BEHAVIOR}

There is no doubt that spinal cord injuries often have devastating consequences for functional outcomes. A large number of studies in rodents (e.g., Anderson et al., 2005; Courtine et al., 2008; Zorner et al., 2010) and monkeys (e.g., Schmidlin et al., 2011; Nout et al., 2012a,b) have investigated the behavioral deficits that occur after spinal cord injury. Other studies have focused on the effects of a restricted interruption of the ascending dorsal column somatosensory pathway on the dexterity of the forepaws in rodents (e.g., McKenna and Whishaw, 1999; Ballermann et al., 2001) and monkeys (e.g., Beck, 1976; Glendinning et al., 1992; Leonard et al., 1992; Cooper et al., 1993; Vierck, 1998; Vierck and Cooper, 1998; Qi et al., 2013). In humans and monkeys, the effects of dorsal column lesions on sensory behavior have been interpreted in two quite different ways in early reports. Thus, Rose and Mountcastle (1959) concluded that the "destruction of the posterior columns in man leads to a loss of the capacity to appreciate the position and movement of the limbs," and "severe"- "disturbance in tactile sensations." Later, Mountcastle further stated, "What remains in the mechanoreceptive sphere after... dorsal column lesion is the capacity to recognize that a mechanical stimulus has occurred; it is no longer possible to specify it exactly as to location, intensity or shape" (Mountcastle and Darian-Smith, 1968). These pronouncements clearly reflect what would be expected after damage of such a major sensory pathway. However, Wall (1970) quite differently concluded that "no sensory defect has been shown to follow isolated dorsal column lesion" in human, and "animals with complete dorsal column section can carry out discriminations of weight, texture, vibration, two points and position.” Later, Azulay and Schwartz (1975) summarized the effects of dorsal column lesion in monkeys by stating that "surprisingly little, if any, tactile functions are impaired after extensive damage to the dorsal funiculus." Subsequent to these early reports, several studies have reported impairments of hand use after lesion of the dorsal columns in macaque monkeys (Glendinning et al., 1992; Leonard et al., 1992), and sensory alterations have been described in macaques (Vierck, 1973, 1974) and humans (Nathan et al., 1986).

How can we explain these great differences in conclusions about the effects of dorsal column lesion in primates? There are several possible reasons for differences in findings and conclusions. (1) One possibility is that different lesions produce different results. For performance with the hand, the dorsal column lesion should be at the $\mathrm{C} 4-\mathrm{C} 5$ level or higher to remove all afferents from the hand, the lower lesions at C5-C6 of the cervical spinal cord spare some afferents from digit 1 and 2, and still lower lesions would spare inputs from most of the hand. Even with C4-C5 lesions or higher, various afferents in the dorsal columns could be spared. (2) Compensations likely occur. As described below for our study of the effects of dorsal column lesions on behavior, vision appears to supplement tactile feedback in food retrieval tasks after dorsal column lesions. Other compensations for sensory impairments are likely to be rapidly acquired as well. (3) Plasticity of the somatosensory system, even in mature primates appears to be a major source of recovery after dorsal column lesions. Recoveries of activation within the system and use of the hand may result from the potentiation of the activating effects of preserved dorsal columns afferents, even when they are very few. This possibility is well demonstrated by the effects of cutting most of the dorsal sensory roots of nerves of the forearm in monkeys, while leaving a few inputs from that hand that initially fail to activate cortex. However, several months later cortex responded to cutaneous stimulation of the largely deafferented digits. Figure 4 illustrates such an example reprinted from Figure 10 of Darian-Smith (2004; see also, Darian-Smith and Brown, 2000; Darian-Smith and Ciferri, 2005, 2006; Darian-Smith, 2009). This reactivation of cortex is due in part to the potentiation of preserved afferents likely through axon growth and the formation of new synaptic contacts on deactivated neurons occurring at brainstem, thalamic, and cortical levels (Darian-Smith and Gilbert, 1994, 1995; Florence et al., 1998; Jain et al., 2000; Darian-Smith et al., 2010). A related possibility is that after dorsal column lesion second-order spinal cord neuron inputs to the cuneate nucleus are also potentiated and thereby come to reactivate that nucleus by touch on the hand, effectively replacing some of the lost direct dorsal column inputs to the cuneate nucleus. We return to this possibility in the last section of this review. (4) Finally, some of the effects attributed to damage to the dorsal columns in previous studies may reflect damage to other afferents, as motor impairments may occur when the lesions extend into the lateral spinal cord where the dorsal lateral funiculus with proprioceptive afferents and the lateral corticospinal motor tract are located.

The results of our recent study of hand use in squirrel monkeys after a unilateral dorsal column lesion provide evidence that the sensory loss produced by lesions confined to the dorsal columns do produce impairments in a food retrieval task (Qi et al., 2013). Monkeys were trained to reach for and retrieve small sugar pellets from wells that ranged from easy (shallow) to difficult (deep). Several results are presented in Figure 5. Before the spinal cord 


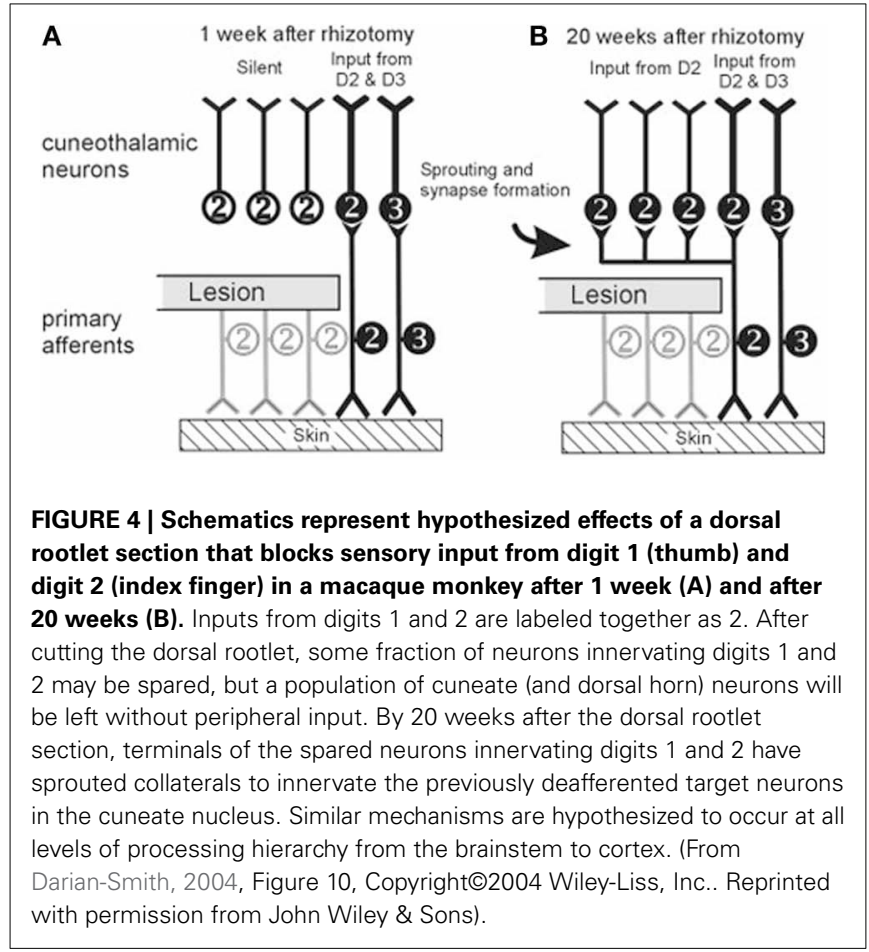

lesion, monkeys were very good at the task, even for the most difficult well. They quickly reached to grasp the pellet after briefly visualizing it, and retrieved it with one or sometimes 2 flexes of the digits to bring the pellet from the well to the mouth. When behavioral testing was continued two weeks after a complete or nearly complete lesion of the dorsal columns, the behavior was clearly impaired in that it took more than one attempt to successfully grasp objects from the difficult wells, and more flexes of the digits were needed. The video recordings of the task performance revealed another change in the behavior. Before the dorsal column lesion, the monkey looked at the pellet in the well only briefly as the monkey started the reach, and instead watched the investigator during the grasp and retrieval. This may seem strange, but extensive visual guidance was unnecessary, and the monkey may regard the investigator as a potential competitor for the food, as it would another monkey, or as potentially dangerous and in need of watching. In contrast, after the lesion, the monkey acted as if it could not sense by touch if the pellet was in the hand, and always looked to see if the pellet was there. During the retrieval, the palm was turned up so the presence of the pellet could be visually confirmed. Overall, we think that the deficits in the retrieval behavior were due to the sensory loss, as they occurred when the lesions did not include motor axons lateral to the dorsal columns. Early successes likely related to behavioral compensations, especially the visual assurance that the pellet had been grasped. In addition, sensory perception likely improved as early as 3-4 weeks after the lesion, as cortex became progressively more responsive to touch on the hand due to cortical reactivation.

\section{MECHANISMS OF CORTICAL REACTIVATION AND THE POTENTIAL FOR THERAPEUTIC TREATMENTS}

The reactivation of deprived hand cortex weeks to months after high cervical dorsal column lesion depends on the potentiation
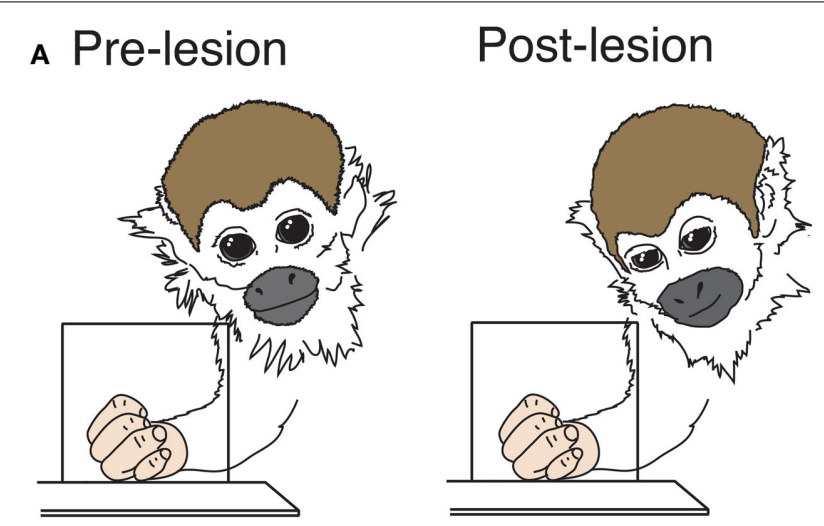

B

\section{Success}

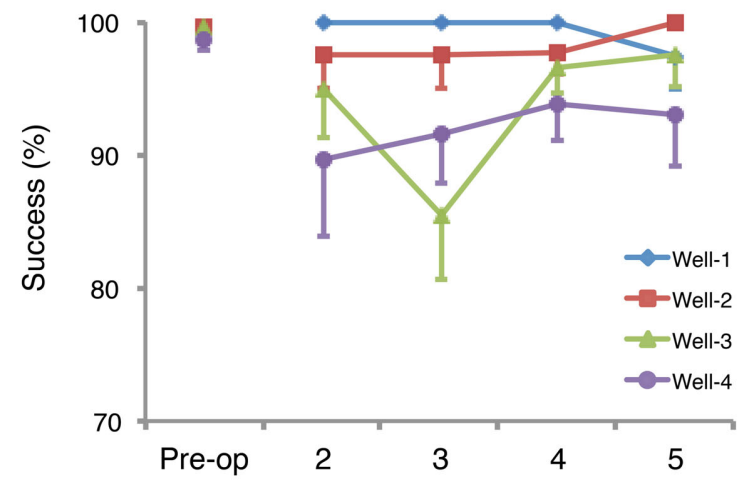

C

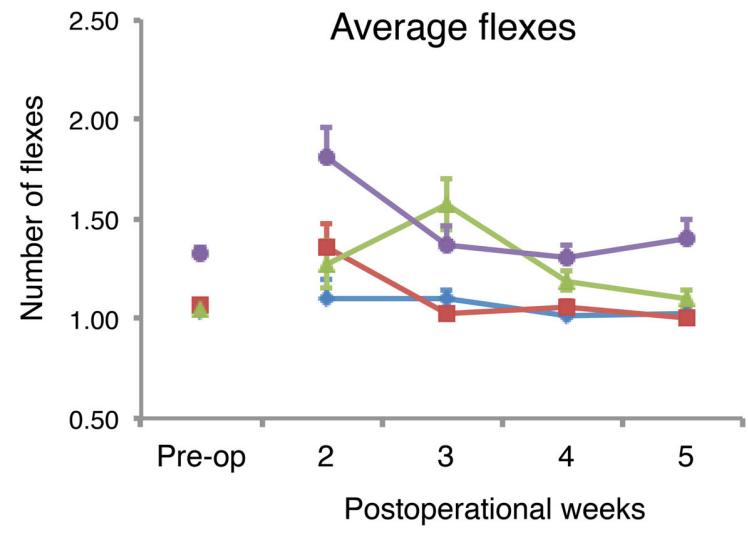

FIGURE 5 | Spontaneous recoveries after dorsal column injury can be incomplete or incorporate various compensations. (A) Drawings from the captured photo-frames taken from a squirrel monkey (SM-O) during the reach-to-grasp task pre-lesion (left) and on post-op Day 15 (right). The schematic summarizes observations that after the spinal cord lesion, monkeys compensate for reduced tactile sensation by relying more often on vision. (B) Post-operational changes in the percentage of successful retrievals (mean, $\pm S D$ ) in the reach-to-grasp task. Success scores in percent of the retrieval success for summed trials from each of the 4 testing wells per post-op week for monkey SM-O. Pre-op final week trials were summed. (C) Post-operational changes in mean number of flexes (mean, $\pm S D$ ) for monkey SM-O. Each data point within each panel is the averaged number of flexes from the sum of the trials from each of the 4 wells over each testing week. Adapted from Qi et al. (2013). 
of preserved sensory pathways through axon growth and the formation of new synapses. We have previously suggested that dorsal column lesions are often incomplete, and that preserved but subthreshold dorsal column inputs to the cuneate nucleus gain strength by forming more synapses on more neurons as the result of reduced competition for synaptic space (Rasmusson and Northgrave, 1997; Xu and Wall, 1997; Darian-Smith, 2004; Darian-Smith and Ciferri, 2006). Similar changes likely occur at the levels of the ventroposterior nucleus and somatosensory cortex (Garraghty et al., 1991, 2006; Rasmusson, 1996; Wellman et al., 2002). Under conditions of extreme loss of afferents to the cuneate nucleus, we had evidence that even afferents from the adjacent trigeminal complex for the face could sprout and grow to innervate the cuneate nucleus (Jain et al., 2000), providing relays to the hand subnucleus of the contralateral ventroposterior nucleus and then to the hand territory of primary somatosensory cortex. While such reactivations of the cuneate nucleus by inputs from the hand that were preserved after the dorsal column lesion, as well as those that grow into the cuneate nucleus from the face, do occur, we have observed reactivations of hand cortex after lesions of the dorsal columns that were 95-100\% complete (Qi et al., 2011a). Although it can be difficult to accurately determine the completeness of a lesion of the dorsal columns from histological sections through the lesion site, we feel confident about the completeness of experimental lesions because we injected tracers into the fingers of both hands in monkeys with unilateral lesions to demonstrate the loss of labeled axon terminations in the cuneate nucleus on the lesioned compared to the non-lesioned side (Qi et al., 2011a). Thus, we have strong evidence that there are reactivations that do not depend on preserved dorsal column first-order afferents, and thus depend mostly on other afferents from the hand.

The most likely alternative pathway is from neurons in the dorsal horn of the spinal cord that project to the dorsal column nuclei (Perl et al., 1962; Rustioni et al., 1979; Bennett et al., 1983). These neurons are directly activated by one of the bifurcated branches of peripheral nerve axons that terminates in the dorsal horn, while the other branch ascends in the dorsal columns and terminates in the dorsal column nuclei (Wall, 1970; Willis and Coggeshall, 2004). These dorsal column neurons would receive the same information for the skin of the hand that the cuneate nucleus directly receives, although there may be differences in the amounts of convergence of inputs and inhibitory mechanisms so that receptive field sizes may differ for neurons in the dorsal horn or cuneate nucleus (Dykes and Craig, 1998; Witham and Baker, 2011). However, the normal role of second-order spinal cord inputs to the cuneate nucleus most likely would be to provide subthreshold activation, because cortical reactivation after a loss of the primary inputs to the cuneate nucleus takes weeks to emerge.

In order to be effective, the projections to the cuneate nucleus by second-order dorsal horn neurons must survive the dorsal column lesion. Some axons from second-order neurons might enter the dorsal columns below the lesion and be lost. Others might enter above the lesion, or travel in some other pathway, such as the lateral funiculus, which is dominated by proprioceptive afferents (Rustioni et al., 1979). This possibility seems likely in that larger

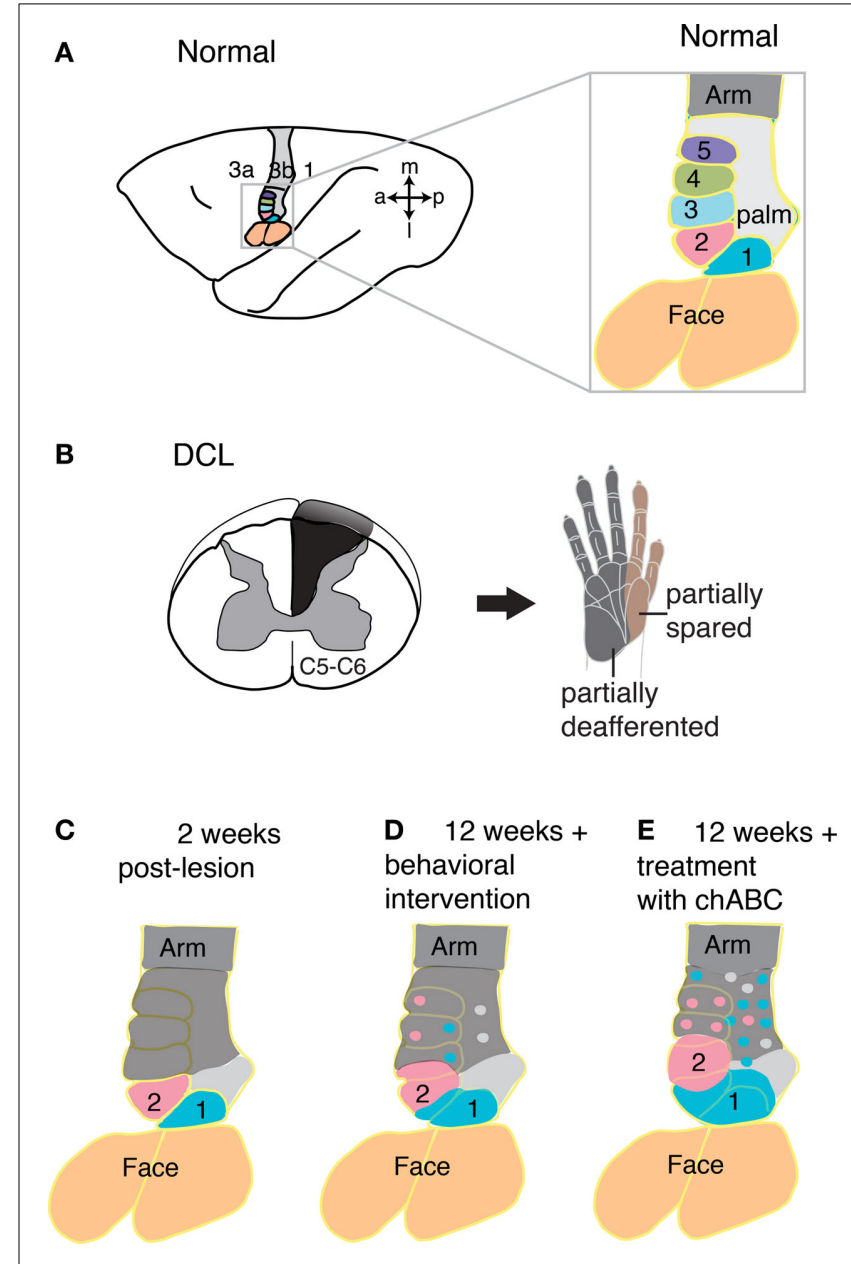

FIGURE 6 | Spontaneous and augmented recoveries from sensory loss in monkey cortex. (A) Schematic view of the left hemisphere of an owl monkey brain with area $3 \mathrm{~b}$ highlighted in color and expanded (right) to focus on the hand representation. (B) When afferents devoted to the hand are cut in the cervical spinal cord at the C5 or C6 level in squirrel monkeys and owl monkeys (left), inputs from much of digit 1 and digit 2 are spared, while inputs from most of the rest of the hand are disrupted, as indicated by the hand schematic (right). (C) After such a lesion (B), the hand representation in primary somatosensory cortex is immediately rendered largely unresponsive to tactile stimuli (gray shading), with the exception of much of the digit 1 and digit 2 representations (blue and pink shading, respectively), for which the majority of axons enter the spinal cord above the level of the lesion. Over weeks of spontaneous post-lesion recovery without augmentation, the deactivated cortex becomes partly reactivated by inputs from the hand with activation from the spared dorsal column inputs (digits 1 and 2), and possibly other pathways (not shown). (D) This schematic summarizes expected results in monkeys with dorsal column lesions that received behavioral intervention when the cortex is studied 12 weeks after the lesion. Sensorimotor training and testing for use of the impaired hand appears to promote reactivation of cortex, but further study is needed to determine how effective behavioral intervention is beyond spontaneous recoveries and in comparison with other types of treatments. Based on previous findings and ongoing research, we expect that the representations of spared digits will expand their territories and islands of responsiveness will emerge in previously unresponsive zones. (E) The effectiveness of a few preserved dorsal column afferents for activating cortex can be enhanced by treatment of the target site in the cuneate nucleus with the enzyme chondroitinase $A B C$ shortly after the spinal cord injury. Digestion of

(Continued) 


\section{FIGURE 6 | Continued}

components of the extracellular matrix in the cuneate that inhibit axon sprouting allows axons spared from the lesion to sprout collaterals and innervate additional territory, which is reflected at the cortical level (examined 12 weeks after lesion and enzyme treatment). Thus, augmentation in this way produces expanded representations of the spared inputs from digits 1 and 2 in cortex, and possibly enhances ability of axons of second-order spinal cord neurons to sprout and innervate islands of the deprived cuneate nucleus. Abbreviations: $1-5$, digits 1-5; 1, 3a and 3b, areas 1, 3a and 3b; a, anterior; C5-6, cervical spinal cord segments 5-6; chABC, chondroitinase $A B C$; $D C L$, dorsal column lesion; I, lateral; $m$, medial; p, posterior. Based on Jain et al. (1997), Bowes et al. (2012), and Qi et al. (2014).

lesions of the dorsal column that extend into the lateral fiber tracts appear to reduce the extent of the reactivation of the hand cortex from inputs from the hand.

Given the evidence that the reactivation of the cortex by inputs from the hand is important for the recovery of manual dexterity, what can be done to promote these reactivations? Recently, we have investigated two interventions for promoting reactivations. First, we found promising evidence that behavioral training after sensory loss improved the recovery of hand use in a retrieval task and correlated with cortical reorganization [Qi et al., 2010, 2012 (abstracts)]. Second, we found that an injection of an enzyme, chondroitinase $\mathrm{ABC}$, into the cuneate nucleus after the lesion of the dorsal columns promotes the reactivation of hand cortex by preserved dorsal column afferents (Bowes et al., 2012). This enzyme digests chondroitin sulphate proteoglycans, which make up the extracellular matrix around neurons and glia. Treatment with chondroitinase $\mathrm{ABC}$ was first shown to promote recovery after spinal cord injury in rats by Bradbury et al. (2002). The extracellular matrix around neurons in the cuneate nucleus provide a chemical and physiological barrier that appears to inhibit new axon growth into and within the nucleus, thereby limiting the reactivation of deprived neurons in the nucleus, and the relay of driven activity to higher levels of the somatosensory system. By intentionally sparing dorsal column afferents from the thumb (digit 1) in squirrel monkeys by placing the dorsal column lesion at a lower cervical level (C6), and using the chondroitinase ABC enzyme injections near the targets for new growth from the spinal cord into the brainstem, more of the hand representation in contralateral somatosensory cortex was activated than in monkeys without this injection (Figure 6). Chondroitinase ABC has been used by others in a number of different experiments to increase axon sprouting, including the growth of dorsal column axons past a lesion site in rats (Massey et al., 2006, see reviews by Onifer et al., 2011; Garcia-Alias and Fawcett, 2012). Other promising treatments for recovery after sensory loss or spinal cord injury include the use of antibodies to a major myelin-associated neurite growth inhibitor, named Nogo-A (see Fawcett et al., 2012). The local placement of factors that promote growth and provide attraction to a target may also be useful (Schnell et al., 1994). Additional treatments for spinal cord injury have been reviewed by others (He and Koprivica, 2004; Buchli and Schwab, 2005; Bradbury and McMahon, 2006; Cafferty et al., 2008; Giger et al., 2010; Cregg et al., 2014; Silva et al., 2014). Sensorimotor training and testing for use of the impaired hand in monkeys (Qi et al., 2013, 2014) or impaired limbs in rodent (Kao et al., 2009; Krajacic et al., 2010; Graziano et al., 2013), appears to promote functional recovery and reactivation of cortex, but further study is needed to determine how effective behavioral intervention is beyond spontaneous recoveries or in relation to pharmacological treatments such as chondroitinase ABC. Combining pharmacological and behavioral interventions may promote even more useful recoveries in primates, as promising results have been reported in rodent models (Tetzlaff et al., 2009; Garcia-Alias and Fawcett, 2012; Zhao et al., 2013). In conclusion, we stress that much progress has been made over the last several years in understanding the recovery process that occurs after sensory loss following dorsal column injury. Much of this plasticity was unexpected, but the spontaneous recovery accounts for the early misinterpretations that the dorsal column pathway has little sensory significance. In addition to the unexpected spontaneous recovery, there are also hopeful signs that various therapeutic treatments have the potential of greatly improving the course of recovery.

\section{AUTHOR CONTRIBUTIONS}

All authors contributed to the writing of the manuscript. The findings reviewed are those of the authors, as well as those of other investigators.

\section{ACKNOWLEDGMENTS}

Our research was supported by NIH grants NS057399 and NS067017 to Hui-Xin Qi; NIH grant NS16446 to Jon H. Kaas, and awards from the Christopher and Dana Reeve Foundation to Jamie L. Reed and to Jon H. Kaas.

\section{REFERENCES}

Aguilar, J., Humanes-Valera, D., Alonso-Calvino, E., Yague, J. G., Moxon, K. A., Oliviero, A., et al. (2010). Spinal cord injury immediately changes the state of the brain. J. Neurosci. 30, 7528-7537. doi: 10.1523/JNEUROSCI.037910.2010

Anderson, K. D., Gunawan, A., and Steward, O. (2005). Quantitative assessment of forelimb motor function after cervical spinal cord injury in rats: relationship to the corticospinal tract. Exp. Neurol. 194, 161-174. doi: 10.1016/j.expneurol.2005.02.006

Azulay, A., and Schwartz, A. S. (1975). The role of the dorsal funiculus of the primate in tactile discrimination. Exp. Neurol. 46, 315-332. doi: 10.1016/00144886(75)90138-7

Ballermann, M., McKenna, J., and Whishaw, I. Q. (2001). A grasp-related deficit in tactile discrimination following dorsal column lesion in the rat. Brain Res. Bull. 54, 237-242. doi: 10.1016/S0361-9230(01)00431-2

Beck, C. (1976). Forelimb performance by squirrel monkeys (Saimiri sciureus) before and after dorsal column lesions. J. Comp. Physiol. Psychol. 90, 353-362. doi: $10.1037 / \mathrm{h} 0077206$

Bennett, G. J., Seltzer, Z., Lu, G. W., Nishikawa, N., and Dubner, R. (1983). The cells of origin of the dorsal column postsynaptic projection in the lumbosacral enlargements of cats and monkeys. Somatosens Res. 1, 131-149. doi: $10.3109 / 07367228309144545$

Bowes, C., Burish, M., Cerkevich, C., and Kaas, J. (2013). Patterns of cortical reorganization in the adult marmoset after a cervical spinal cord injury. J. Comp. Neurol. 521, 3451-3463. doi: 10.1002/cne.23360

Bowes, C., Massey, J. M., Burish, M., Cerkevich, C. M., and Kaas, J. H. (2012) Chondroitinase $\mathrm{ABC}$ promotes selective reactivation of somatosensory cortex in squirrel monkeys after a cervical dorsal column lesion. Proc. Natl. Acad. Sci. U.S.A. 109, 2595-2600. doi: 10.1073/pnas.1121604109

Bradbury, E. J., and McMahon, S. B. (2006). Spinal cord repair strategies: why do they work? Nat. Rev. Neurosci. 7, 644-653. doi: 10.1038/nrn1964 
Bradbury, E. J., Moon, L. D., Popat, R. J., King, V. R., Bennett, G. S., Patel, P. N., et al. (2002). Chondroitinase ABC promotes functional recovery after spinal cord injury. Nature 416, 636-640. doi: 10.1038/416636a

Brugger, P., Kollias, S. S., Muri, R. M., Crelier, G., Hepp-Reymond, M. C., and Regard, M. (2000). Beyond re-membering: phantom sensations of congenitally absent limbs. Proc. Natl. Acad. Sci. U.S.A. 97, 6167-6172. doi: 10.1073/pnas. 100510697

Buchli, A. D., and Schwab, M. E. (2005). Inhibition of Nogo: a key strategy to increase regeneration, plasticity and functional recovery of the lesioned central nervous system. Ann. Med. 37, 556-567. doi: 10.1080/07853890500407520

Buonomano, D. V., and Merzenich, M. M. (1998). Cortical plasticity: from synapses to maps. Annu. Rev. Neurosci. 21, 149-186. doi: 10.1146/annurev.neuro.21.1.149

Burton, H., Sathian, K., and Shao, D. H. (1990). Altered responses to cutaneous stimuli in the second somatosensory cortex following lesions of the postcentral gyrus in infant and juvenile macaques. J. Comp. Neurol. 291, 395-414. doi: $10.1002 /$ cne. 902910307

Cafferty, W. B., McGee, A. W., and Strittmatter, S. M. (2008). Axonal growth therapeutics: regeneration or sprouting or plasticity? Trends Neurosci. 31, 215-220. doi: 10.1016/j.tins.2008.02.004

Calford, M. B., and Tweedale, R. (1988). Immediate and chronic changes in responses of somatosensory cortex in adult flying-fox after digit amputation. Nature 332, 446-448. doi: 10.1038/332446a0

Cheetham, C. E., Hammond, M. S., McFarlane, R., and Finnerty, G. T. (2008). Altered sensory experience induces targeted rewiring of local excitatory connections in mature neocortex. J. Neurosci. 28, 9249-9260. doi: 10.1523/JNEUROSCI.2974-08.2008

Chen, L. M., Qi, H. X., and Kaas, J. H. (2012). Dynamic reorganization of digit representations in somatosensory cortex of nonhuman primates after spinal cord injury. J. Neurosci. 32, 14649-14663. doi: 10.1523/JNEUROSCI.1841-12.2012

Chino, Y., Smith, E. L. 3rd., Zhang, B., Matsuura, K., Mori, T., and Kaas, J. H. (2001). Recovery of binocular responses by cortical neurons after early monocular lesions. Nat. Neurosci. 4, 689-690. doi: 10.1038/89469

Chino, Y. M., Smith, E. L. 3rd., Kaas, J. H., Sasaki, Y., and Cheng, H. (1995). Receptive-field properties of deafferentated visual cortical neurons after topographic map reorganization in adult cats. J. Neurosci. 15, 2417-2433.

Cooper, B. Y., Glendinning, D. S., and Vierck, C. J. Jr. (1993). Finger movement deficits in the stumptail macaque following lesions of the fasciculus cuneatus. Somatosens Mot. Res. 10, 17-29. doi: 10.3109/08990229309028820

Courtine, G., Song, B., Roy, R. R., Zhong, H., Herrmann, J. E., Ao, Y., et al. (2008). Recovery of supraspinal control of stepping via indirect propriospinal relay connections after spinal cord injury. Nat. Med. 14, 69-74. doi: 10.1038/ $\mathrm{nm} 1682$

Cregg, J. M., Depaul, M. A., Filous, A. R., Lang, B. T., Tran, A., and Silver, J. (2014). Functional regeneration beyond the glial scar. Exp. Neurol. 253C, 197-207. doi: 10.1016/j.expneurol.2013.12.024

Crockett, D. P., Maslany, S., Harris, S. L., and Egger, M. D. (1993). Enhanced cytochrome-oxidase staining of the cuneate nucleus in the rat reveals a modifiable somatotopic map. Brain Res. 612, 41-55. doi: 10.1016/00068993(93)91642-6

Curt, A., Alkadhi, H., Crelier, G. R., Boendermaker, S. H., Hepp-Reymond, M. C., and Kollias, S. S. (2002). Changes of non-affected upper limb cortical representation in paraplegic patients as assessed by fMRI. Brain 125, 2567-2578. doi: 10.1093/brain/awf250

Cusick, C. G., and Gould, H. J. 3rd. (1990). Connections between area 3b of the somatosensory cortex and subdivisions of the ventroposterior nuclear complex and the anterior pulvinar nucleus in squirrel monkeys. J. Comp. Neurol. 292, 83-102. doi: 10.1002/cne.902920106

D'Amato, C. J., and Hicks, S. P. (1978). Normal development and post-traumatic plasticity of corticospinal neurons in rats. Exp. Neurol. 60, 557-569. doi: 10.1016/0014-4886(78)90010-9

Darian-Smith, C. (2004). Primary afferent terminal sprouting after a cervical dorsal rootlet section in the macaque monkey. J. Comp. Neurol. 470, 134-150. doi: $10.1002 /$ cne. 11030

Darian-Smith, C. (2009). Synaptic plasticity, neurogenesis, and functional recovery after spinal cord injury. Neuroscientist 15, 149-165. doi: 10.1177/ 1073858408331372

Darian-Smith, C., and Brown, S. (2000). Functional changes at periphery and cortex following dorsal root lesions in adult monkeys. Nat. Neurosci. 3, 476-481. doi: $10.1038 / 74852$
Darian-Smith, C., and Ciferri, M. (2006). Cuneate nucleus reorganization following cervical dorsal rhizotomy in the macaque monkey: its role in the recovery of manual dexterity. J. Comp. Neurol. 498, 552-565. doi: 10.1002/cne.21088

Darian-Smith, C., and Ciferri, M. M. (2005). Loss and recovery of voluntary hand movements in the macaque following a cervical dorsal rhizotomy. J. Comp. Neurol. 491, 27-45. doi: 10.1002/cne.20686

Darian-Smith, C., and Gilbert, C. D. (1994). Axonal sprouting accompanies functional reorganization in adult cat striate cortex. Nature 368, 737-740. doi: $10.1038 / 368737 \mathrm{a} 0$

Darian-Smith, C., and Gilbert, C. D. (1995). Topographic reorganization in the striate cortex of the adult cat and monkey is cortically mediated. J. Neurosci. 15, $1631-1647$.

Darian-Smith, C., Hopkins, S., and Ralston, H. J. 3rd. (2010). Changes in synaptic populations in the spinal dorsal horn following a dorsal rhizotomy in the monkey. J. Comp. Neurol. 518, 103-117. doi: 10.1002/cne.22216

Davis, K. D., Kiss, Z. H., Luo, L., Tasker, R. R., Lozano, A. M., and Dostrovsky, J. O. (1998). Phantom sensations generated by thalamic microstimulation. Nature 391, 385-387. doi: 10.1038/34905

Disbrow, E., Litinas, E., Recanzone, G. H., Padberg, J., and Krubitzer, L. (2003). Cortical connections of the second somatosensory area and the parietal ventral area in macaque monkeys. J. Comp. Neurol. 462, 382-399. doi: $10.1002 /$ cne. 10731

Doetsch, G. S., Harrison, T. A., Macdonald, A. C., and Litaker, M. S. (1996). Shortterm plasticity in primary somatosensory cortex of the rat: rapid changes in magnitudes and latencies of neuronal responses following digit denervation. Exp. Brain Res. 112, 505-512. doi: 10.1007/BF00227956

Dutta, A., Kambi, N., Raghunathan, P., Khushu, S., and Jain, N. (2013). Large-scale reorganization of the somatosensory cortex of adult macaque monkeys revealed by fMRI. Brain Struct. Funct. doi: 10.1007/s00429-013-0569-8. [Epub ahead of print].

Dykes, R. W., and Craig, A. D. (1998). Control of size and excitability of mechanosensory receptive fields in dorsal column nuclei by homolateral dorsal horn neurons. J. Neurophysiol. 80, 120-129.

Elbert, T., Sterr, A., Flor, H., Rockstroh, B., Knecht, S., Pantev, C., et al. (1997). Input-increase and input-decrease types of cortical reorganization after upper extremity amputation in humans. Exp. Brain Res. 117, 161-164. doi: $10.1007 / \mathrm{s} 002210050210$

Faggin, B. M., Nguyen, K. T., and Nicolelis, M. A. (1997). Immediate and simultaneous sensory reorganization at cortical and subcortical levels of the somatosensory system. Proc. Natl. Acad. Sci. U.S.A. 94, 9428-9433. doi: 10.1073/pnas.94.17.9428

Fang, P. C., Stepniewska, I., and Kaas, J. H. (2005). Ipsilateral cortical connections of motor, premotor, frontal eye, and posterior parietal fields in a prosimian primate, Otolemur garnetti. J. Comp. Neurol. 490, 305-333. doi: $10.1002 /$ cne. 20665

Fawcett, J. W., Schwab, M. E., Montani, L., Brazda, N., and Muller, H. W. (2012). Defeating inhibition of regeneration by scar and myelin components. Handb. Clin. Neurol. 109, 503-522. doi: 10.1016/B978-0-444-52137-8.00031-0

Flor, H., Elbert, T., Knecht, S., Wienbruch, C., Pantev, C., Birbaumer, N. et al. (1995). Phantom-limb pain as a perceptual correlate of cortical reorganization following arm amputation. Nature 375, 482-484. doi: 10.1038/ $375482 \mathrm{a} 0$

Flor, H., Elbert, T., Muhlnickel, W., Pantev, C., Wienbruch, C., and Taub, E. (1998). Cortical reorganization and phantom phenomena in congenital and traumatic upper-extremity amputees. Exp. Brain Res. 119, 205-212. doi: $10.1007 / \mathrm{s} 002210050334$

Florence, S. L., Hackett, T. A., and Strata, F. (2000). Thalamic and cortical contributions to neural plasticity after limb amputation. J. Neurophysiol. 83, 3154-3159.

Florence, S. L., and Kaas, J. H. (1995). Large-scale reorganization at multiple levels of the somatosensory pathway follows therapeutic amputation of the hand in monkeys. J. Neurosci. 15, 8083-8095.

Florence, S. L., Taub, H. B., and Kaas, J. H. (1998). Large-scale sprouting of cortical connections after peripheral injury in adult macaque monkeys. Science 282 , 1117-1121. doi: 10.1126/science.282.5391.1117

Garcia-Alias, G., and Fawcett, J. W. (2012). Training and anti-CSPG combination therapy for spinal cord injury. Exp. Neurol. 235, 26-32. doi: 10.1016/j.expneurol.2011.09.009

Garraghty, P. E., Arnold, L. L., Wellman, C. L., and Mowery, T. M. (2006). Receptor autoradiographic correlates of deafferentation-induced reorganization 
in adult primate somatosensory cortex. J. Comp. Neurol. 497, 636-645. doi: $10.1002 /$ cne. 21018

Garraghty, P. E., Florence, S. L., and Kaas, J. H. (1990a). Ablations of areas 3a and 3b of monkey somatosensory cortex abolish cutaneous responsivity in area 1 . Brain Res. 528, 165-169. doi: 10.1016/0006-8993(90)90213-U

Garraghty, P. E., Lachica, E. A., and Kaas, J. H. (1991). Injury-induced reorganization of somatosensory cortex is accompanied by reductions in GABA staining. Somatosens Mot. Res. 8, 347-354. doi: 10.3109/08990229109144757

Garraghty, P. E., Pons, T. P., and Kaas, J. H. (1990b). Ablations of areas 3b (SI proper) and 3a of somatosensory cortex in marmosets deactivate the second and parietal ventral somatosensory areas. Somatosens Mot. Res. 7, 125-135. doi: 10.3109/08990229009144703

Ghosh, A., Sydekum, E., Haiss, F., Peduzzi, S., Zorner, B., Schneider, R., et al. (2009). Functional and anatomical reorganization of the sensory-motor cortex after incomplete spinal cord injury in adult rats. J. Neurosci. 29, 12210-12219. doi: 10.1523/JNEUROSCI.1828-09.2009

Giger, R. J., Hollis, E. R. 2nd., and Tuszynski, M. H. (2010). Guidance molecules in axon regeneration. Cold Spring Harb. Perspect. Biol. 2, a001867. doi: 10.1101/cshperspect.a001867

Glendinning, D. S., Cooper, B. Y., Vierck, C. J. Jr., and Leonard, C. M. (1992). Altered precision grasping in stumptail macaques after fasciculus cuneatus lesions. Somatosens Mot. Res. 9, 61-73. doi: 10.3109/08990229209144763

Graziano, A., Foffani, G., Knudsen, E. B., Shumsky, J., and Moxon, K. A. (2013). Passive exercise of the hind limbs after complete thoracic transection of the spinal cord promotes cortical reorganization. PLOS ONE 8:e54350. doi: 10.1371/journal.pone.0054350

Graziano, A., and Jones, E. G. (2009). Early withdrawal of axons from higher centers in response to peripheral somatosensory denervation. J. Neurosci. 29, 3738-3748. doi: 10.1523/JNEUROSCI.5388-08.2009

He, Z., and Koprivica, V. (2004). The Nogo signaling pathway for regeneration block. Annu. Rev. Neurosci. 27, 341-368. doi: 10.1146/annurev.neuro.27.070203. 144340

Hickmott, P. W., and Steen, P. A. (2005). Large-scale changes in dendritic structure during reorganization of adult somatosensory cortex. Nat. Neurosci. 8, 140-142. doi: $10.1038 / \mathrm{nn} 1384$

Hicks, S. P., and D'Amato, C. J. (1975). Motor-sensory cortex-corticospinal system and developing locomotion and placing in rats. Am. J. Anat. 143, 1-42. doi 10.1002/aja.1001430102

Humanes-Valera, D., Aguilar, J., and Foffani, G. (2013). Reorganization of the intact somatosensory cortex immediately after spinal cord injury. PLoS ONE 8:e69655. doi: 10.1371/journal.pone.0069655

Jain, N., Catania, K. C., and Kaas, J. H. (1997). Deactivation and reactivation of somatosensory cortex after dorsal spinal cord injury. Nature 386, 495-498. doi: $10.1038 / 386495 \mathrm{a} 0$

Jain, N., Catania, K. C., and Kaas, J. H. (1998). A histologically visible representation of the fingers and palm in primate area $3 \mathrm{~b}$ and its immutability following long-term deafferentations. Cereb. Cortex 8, 227-236. doi: 10.1093/cercor/8.3.227

Jain, N., Florence, S. L., Qi, H. X., and Kaas, J. H. (2000). Growth of new brainstem connections in adult monkeys with massive sensory loss. Proc. Natl. Acad. Sci. U.S.A. 97, 5546-5550. doi: 10.1073/pnas.090572597

Jain, N., Qi, H. X., Catania, K. C., and Kaas, J. H. (2001). Anatomic correlates of the face and oral cavity representations in the somatosensory cortical area 3b of monkeys. J. Comp. Neurol. 429, 455-468. doi: 10.1002/10969861(20010115)429:3\%3C455::AID-CNE7\%3E3.0.CO;2-F

Jain, N., Qi, H. X., Collins, C. E., and Kaas, J. H. (2008). Large-scale reorganization in the somatosensory cortex and thalamus after sensory loss in macaque monkeys. J. Neurosci. 28, 11042-11060. doi: 10.1523/JNEUROSCI.233408.2008

Jones, E. G. (2000). Cortical and subcortical contributions to activity-dependent plasticity in primate somatosensory cortex. Annu. Rev. Neurosci. 23, 1-37. doi 10.1146/annurev.neuro.23.1.1

Jones, E. G., Friedman, D. P., and Hendry, S. H. (1982). Thalamic basis of place- and modality-specific columns in monkey somatosensory cortex: a correlative anatomical and physiological study. J. Neurophysiol. 48, $545-568$.

Jones, E. G., and Pons, T. P. (1998). Thalamic and brainstem contributions to largescale plasticity of primate somatosensory cortex. Science 282, 1121-1125. doi: $10.1126 /$ science.282.5391.1121
Kaas, J. H. (2012). "Somatosensory system," in The Human Nervous System. 3rd Edn, eds J. K. Mai and G. Paxinos. (London: ElsevierAcademic Press), 1064-1099.

Kaas, J. H., Nelson, R. J., Sur, M., Dykes, R. W., and Merzenich, M. M. (1984). The somatotopic organization of the ventroposterior thalamus of the squirrel monkey, Saimiri sciureus. J. Comp. Neurol. 226, 111-140. doi: $10.1002 /$ cne. 902260109

Kaas, J. H., Nelson, R. J., Sur, M., Lin, C. S., and Merzenich, M. M. (1979). Multiple representations of the body within the primary somatosensory cortex of primates. Science 204, 521-523. doi: 10.1126/science.107591

Kaas, J. H., Qi, H. X., Burish, M. J., Gharbawie, O. A., Onifer, S. M., and Massey, J. M. (2008). Cortical and subcortical plasticity in the brains of humans, primates, and rats after damage to sensory afferents in the dorsal columns of the spinal cord. Exp. Neurol. 209, 407-416. doi: 10.1016/j.expneurol.2007.06.014

Kaas, J. H., Qi, H. X., and Iyengar, S. (2006). Cortical network for representing the teeth and tongue in primates. Anat. Rec. A Discov. Mol. Cell Evol. Biol. 288, 182-190. doi: 10.1002/ar.a.20267

Kambi, N., Tandon, S., Mohammed, H., Lazar, L., and Jain, N. (2011) Reorganization of the primary motor cortex of adult macaque monkeys after sensory loss resulting from partial spinal cord injuries. J. Neurosci. 31, 3696-3707. doi: 10.1523/JNEUROSCI.5187-10.2011

Kao, T., Shumsky, J. S., Murray, M., and Moxon, K. A. (2009). Exercise induces cortical plasticity after neonatal spinal cord injury in the rat. J. Neurosci. 29, 7549-7557. doi: 10.1523/JNEUROSCI.2474-08.2009

Kelahan, A. M., and Doetsch, G. S. (1984). Time-dependent changes in the functional organization of somatosensory cerebral cortex following digit amputation in adult raccoons. Somatosens Res. 2, 49-81.

Krajacic, A., Weishaupt, N., Girgis, J., Tetzlaff, W., and Fouad, K. (2010). Traininginduced plasticity in rats with cervical spinal cord injury: effects and side effects. Behav. Brain Res. 214, 323-331. doi: 10.1016/j.bbr.2010.05.053

Krubitzer, L. A., and Kaas, J. H. (1990). The organization and connections of somatosensory cortex in marmosets. J. Neurosci. 10, 952-974.

Krupa, D. J., Ghazanfar, A. A., and Nicolelis, M. A. (1999). Immediate thalamic sensory plasticity depends on corticothalamic feedback. Proc. Natl. Acad. Sci. U.S.A. 96, 8200-8205. doi: 10.1073/pnas.96.14.8200

Leonard, C. M., Glendinning, D. S., Wilfong, T., Cooper, B. Y., and Vierck, C. J. Jr. (1992). Alterations of natural hand movements after interruption of fasciculus cuneatus in the macaque. Somatosens Mot. Res. 9, 75-89. doi: $10.3109 / 08990229209144764$

Li, C. X., Yang, Q., Vemulapalli, S., and Waters, R. S. (2013). Forelimb amputationinduced reorganization in the cuneate nucleus $(\mathrm{CN})$ is not reflected in largescale reorganization in rat forepaw barrel subfield cortex (FBS). Brain Res. 1526, 26-43. doi: 10.1016/j.brainres.2013.05.049

Liao, C. C., Gharbawie, O. A., Qi, H., and Kaas, J. H. (2013). Cortical connections to single digit representations in area $3 \mathrm{~b}$ of somatosensory cortex in squirrel monkeys and prosimian galagos. J. Comp. Neurol. 521, 3768-3790. doi: $10.1002 / \mathrm{cne} .23377$

Lotze, M., Grodd, W., Birbaumer, N., Erb, M., Huse, E., and Flor, H. (1999). Does use of a myoelectric prosthesis prevent cortical reorganization and phantom limb pain? Nat. Neurosci. 2, 501-502. doi: 10.1038/9145

Marik, S. A., Yamahachi, H., McManus, J. N., Szabo, G., and Gilbert, C. D. (2010). Axonal dynamics of excitatory and inhibitory neurons in somatosensory cortex PLoS Biol. 8:e1000395. doi: 10.1371/journal.pbio.1000395

Marik, S. A., Yamahachi, H., Meyer Zum Alten Borgloh, S., and Gilbert, C. D. (2014). Large-Scale Axonal Reorganization of Inhibitory Neurons following Retinal Lesions. J. Neurosci. 34, 1625-1632. doi: 10.1523/JNEUROSCI.434513.2014.

Massey, J. M., Hubscher, C. H., Wagoner, M. R., Decker, J. A., Amps, J., Silver, J., et al. (2006). Chondroitinase ABC digestion of the perineuronal net promotes functional collateral sprouting in the cuneate nucleus after cervical spinal cord injury. J. Neurosci. 26, 4406-4414. doi: 10.1523/JNEUROSCI.546705.2006

McKenna, J. E., and Whishaw, I. Q. (1999). Complete compensation in skilled reaching success with associated impairments in limb synergies, after dorsal column lesion in the rat. J. Neurosci. 19, 1885-1894.

Merzenich, M. M., Kaas, J. H., Sur, M., and Lin, C. S. (1978). Double representation of the body surface within cytoarchitectonic areas $3 b$ and 1 in "SI" in the owl monkey (Aotus trivirgatus). J. Comp. Neurol. 181, 41-73. doi: $10.1002 /$ cne. 901810104 
Merzenich, M. M., Kaas, J. H., Wall, J., Nelson, R. J., Sur, M., and Felleman, D. (1983a). Topographic reorganization of somatosensory cortical areas $3 \mathrm{~b}$ and 1 in adult monkeys following restricted deafferentation. Neuroscience 8, 33-55. doi: 10.1016/0306-4522(83)90024-6

Merzenich, M. M., Kaas, J. H., Wall, J. T., Sur, M., Nelson, R. J., and Felleman, D. J. (1983b). Progression of change following median nerve section in the cortical representation of the hand in areas $3 \mathrm{~b}$ and 1 in adult owl and squirrel monkeys. Neuroscience 10, 639-665. doi: 10.1016/0306-4522(83) 90208-7

Moore, C. I., Stern, C. E., Dunbar, C., Kostyk, S. K., Gehi, A., and Corkin, S. (2000). Referred phantom sensations and cortical reorganization after spinal cord injury in humans. Proc. Natl. Acad. Sci. U.S.A. 97, 14703-14708. doi: 10.1073/pnas.250348997

Mountcastle, V. B., and Darian-Smith, I. (1968). "Neural mechanisms in somesthesia," in Medical Physiology, ed V. B. Mountcastle (St. Louis, MO: C. V. Mosby), 1372-1423.

Nathan, P. W., Smith, M. C., and Cook, A. W. (1986). Sensory effects in man of lesions of the posterior columns and of some other afferent pathways. Brain 109(Pt. 5), 1003-1041.

Nelson, R. J., and Kaas, J. H. (1981). Connections of the ventroposterior nucleus of the thalamus with the body surface representations in cortical areas $3 \mathrm{~b}$ and 1 of the cynomolgus macaque, (Macaca fascicularis). J. Comp. Neurol. 199, 29-64. doi: 10.1002/cne.901990104

Nelson, R. J., Sur, M., Felleman, D. J., and Kaas, J. H. (1980). Representations of the body surface in postcentral parietal cortex of Macaca fascicularis. J. Comp Neurol. 192, 611-643. doi: 10.1002/cne.901920402

Nout, Y. S., Ferguson, A. R., Strand, S. C., Moseanko, R., Hawbecker, S., Zdunowski, S., et al. (2012b). Methods for functional assessment after C7 spinal cord hemisection in the rhesus monkey. Neurorehabil. Neural Repair 26, 556-569. doi: $10.1177 / 1545968311421934$

Nout, Y. S., Rosenzweig, E. S., Brock, J. H., Strand, S. C., Moseanko, R., Hawbecker S., et al. (2012a). Animal models of neurologic disorders: a nonhuman primate model of spinal cord injury. Neurotherapeutics 9, 380-392. doi: 10.1007/s13311012-0114-0

Onifer, S. M., Smith, G. M., and Fouad, K. (2011). Plasticity after spinal cord injury: relevance to recovery and approaches to facilitate it. Neurotherapeutics 8, 283-293. doi: 10.1007/s13311-011-0034-4

Paxino, G., and Watson, C. (2007). The Rat Brain in Stereotaxic Coordinates Amsterdam: Elsevier.

Pei, Y. C., Denchev, P. V., Hsiao, S. S., Craig, J. C., and Bensmaia, S. J. (2009). Convergence of submodality-specific input onto neurons in primary somatosensory cortex. J. Neurophysiol. 102, 1843-1853. doi: 10.1152/jn. 00235.2009

Perl, E. R., Whitlock, D. G., and Gentry, J. R. (1962). Cutaneous projection to second-order neurons of the dorsal column system. J. Neurophysiol. 25 337-358.

Pons, T. P., Garraghty, P. E., Friedman, D. P., and Mishkin, M. (1987). Physiological evidence for serial processing in somatosensory cortex. Science 237, 417-420. doi: $10.1126 /$ science. 3603028

Pons, T. P., Garraghty, P. E., and Mishkin, M. (1992). Serial and parallel processing of tactual information in somatosensory cortex of rhesus monkeys. J. Neurophysiol. 68, 518-527.

Pons, T. P., Garraghty, P. E., Ommaya, A. K., Kaas, J. H., Taub, E., and Mishkin, M. (1991). Massive cortical reorganization after sensory deafferentation in adult macaques. Science 252, 1857-1860. doi: 10.1126/science.1843843

Qi, H. X., Chen, L. M., and Kaas, J. H. (2011a). Reorganization of somatosensory cortical areas $3 \mathrm{~b}$ and 1 after unilateral section of dorsal columns of the spinal cord in squirrel monkeys. J. Neurosci. 31, 13662-13675. doi: 10.1523/JNEUROSCI.2366-11.2011

Qi, H. X., Gharbawie, O. A., Wong, P., and Kaas, J. H. (2011b). Cell-poor septa separate representations of digits in the ventroposterior nucleus of the thalamus in monkeys and prosimian galagos. J. Comp. Neurol. 519, 738-758. doi: $10.1002 / \mathrm{cne} .22545$

Qi, H. X., Gharbawie, O. A., Wynne, K. W., and Kaas, J. H. (2013). Impairment and recovery of hand use after unilateral section of the dorsal columns of the spinal cord in squirrel monkeys. Behav. Brain Res. 252, 363-376. doi: 10.1016/j.bbr.2013.05.058

Qi, H. X., Jain, N., Collins, C. E., Lyon, D. C., and Kaas, J. H. (2010). Functional organization of motor cortex of adult macaque monkeys is altered by sensory loss in infancy. Proc. Natl. Acad. Sci. U.S.A. 107, 3192-3197. doi: 10.1073/pnas. 0914962107

Qi, H. X., and Kaas, J. H. (2004). Myelin stains reveal an anatomical framework for the representation of the digits in somatosensory area $3 \mathrm{~b}$ of macaque monkeys. J. Comp. Neurol. 477, 172-187. doi: 10.1002/cne.20247

Qi, H. X., Reed, J. L., Bui, T., Chen, L. M., and Kaas, J. H. (2012). Longitudinal fMRI and behavioral recovery after sensory loss from the hand of adult monkeys. Fed. Euro. Neurosci. Soc. Forum Abstr. A-471-0142-02394.

Qi, H. X., Reed, J. L., Gharbawie, O. A., Burish, M. J., and Kaas, J. H. (2014). Cortical neuron response properties are related to lesion extent and behavioral recovery after sensory loss from spinal cord injury in monkeys. J. Neurosci. 34, 4345-4363. doi: 10.1523/JNEUROSCI.4954-13.2014

Ramachandran, V. S. (1993). Behavioral and magnetoencephalographic correlates of plasticity in the adult human brain. Proc. Natl. Acad. Sci. U.S.A. 90, 10413-10420. doi: 10.1073/pnas.90.22.10413

Ramachandran, V. S., and Rogers-Ramachandran, D. (2000). Phantom limbs and neural plasticity. Arch. Neurol. 57, 317-320. doi: 10.1001/archneur.5 7.3.317

Rasmusson, D. D. (1996). Changes in the response properties of neurons in the ventroposterior lateral thalamic nucleus of the raccoon after peripheral deafferentation. J. Neurophysiol. 75, 2441-2450.

Rasmusson, D. D., and Northgrave, S. A. (1997). Reorganization of the raccoon cuneate nucleus after peripheral denervation. J. Neurophysiol. 78, 2924-2936.

Reed, J. L., Qi, H. X., and Kaas, J. H. (2012). Ipsilateral responses and interhemispheric interactions in area $3 \mathrm{~b}$ after dorsal column spinal cord injury in New World monkeys. Soc. Neurosci. Abstr. 42.

Reed, J. L., Qi, H. X., Zhou, Z., Bernard, M. R., Burish, M. J., Bonds, A. B., et al (2010). Response properties of neurons in primary somatosensory cortex of owl monkeys reflect widespread spatiotemporal integration. J. Neurophysiol. 103, 2139-2157. doi: 10.1152/jn.00709.2009

Rose, J. E., and Mountcastle, V. B. (1959). "Touch and kinesthesis," in Handbook of Physilogy, ed H. W. Magoun (Washington, DC: American Physiology Society), 387-429.

Rustioni, A., Hayes, N. L., and O’Neill, S. (1979). Dorsal column nuclei and ascending spinal afferents in macaques. Brain 102, 95-125. doi: 10.1093/brain/102.1.95

Schmidlin, E., Kaeser, M., Gindrat, A. D., Savidan, J., Chatagny, P., Badoud, S., et al (2011). Behavioral assessment of manual dexterity in non-human primates. J. Vis. Exp. 57, 3258-3270. doi: 10.3791/3258

Schnell, L., Schneider, R., Kolbeck, R., Barde, Y. A., and Schwab, M. E. (1994) Neurotrophin-3 enhances sprouting of corticospinal tract during development and after adult spinal cord lesion. Nature 367, 170-173. doi: 10.1038/ $367170 \mathrm{a} 0$

Sengelaub, D. R., Muja, N., Mills, A. C., Myers, W. A., Churchill, J. D., and Garraghty, P. E. (1997). Denervation-induced sprouting of intact peripheral afferents into the cuneate nucleus of adult rats. Brain Res. 769, 256-262. doi: 10.1016/S0006-8993(97)00708-7

Silva, A. C., Rasey, S. K., Wu, X., and Wall, J. T. (1996). Initial cortical reactions to injury of the median and radial nerves to the hands of adult primates. J. Comp. Neurol. 366, 700-716. doi: 10.1002/(SICI)10969861(19960318)366:4\&lt;700::AID-CNE9\&gt;3.0.CO;2-8

Silva, N. A., Sousa, N., Reis, R. L., and Salgado, A. J. (2014). From basics to clinical: a comprehensive review on spinal cord injury. Prog. Neurobiol. 114, 25-57. doi: 10.1016/j.pneurobio.2013.11.002

Stepniewska, I., Preuss, T. M., and Kaas, J. H. (1993). Architectonics, somatotopic organization, and ipsilateral cortical connections of the primary motor area (M1) of owl monkeys. J. Comp. Neurol. 330, 238-271. doi: $10.1002 / \mathrm{cne} .903300207$

Sur, M., Nelson, R. J., and Kaas, J. H. (1982). Representations of the body surface in cortical areas $3 \mathrm{~b}$ and 1 of squirrel monkeys: comparisons with other primates. J. Comp. Neurol. 211, 177-192. doi: 10.1002/cne.902110207

Sur, M., Wall, J. T., and Kaas, J. H. (1984). Modular distribution of neurons with slowly adapting and rapidly adapting responses in area $3 \mathrm{~b}$ of somatosensory cortex in monkeys. J. Neurophysiol. 51, 724-744.

Tandon, S., Kambi, N., Lazar, L., Mohammed, H., and Jain, N. (2009). Large-scale expansion of the face representation in somatosensory areas of the lateral sulcus after spinal cord injuries in monkeys. J. Neurosci. 29, 12009-12019. doi: 10.1523/JNEUROSCI.2118-09.2009

Tetzlaff, W., Fouad, K., and Kwon, B. (2009). Be careful what you train for. Nat. Neurosci. 12, 1077-1079. doi: 10.1038/nn0909-1077 
Tommerdahl, M., Whitsel, B. L., Vierck, C. J. Jr., Favorov, O., Juliano, S., Cooper, B., et al. (1996). Effects of spinal dorsal column transection on the response of monkey anterior parietal cortex to repetitive skin stimulation. Cereb. Cortex 6, 131-155. doi: 10.1093/cercor/6.2.131

Turrigiano, G. G. (1999). Homeostatic plasticity in neuronal networks: the more things change, the more they stay the same. Trends Neurosci. 22, 221-227. doi: 10.1016/S0166-2236(98)01341-1

Vahlsing, H. L., and Feringa, E. R. (1980). A ventral uncrossed corticospinal tract in the rat. Exp. Neurol. 70, 282-287. doi: 10.1016/0014-4886(80)90027-8

Vierck, C. J. Jr. (1973). Alterations of spatio-tactile discrimination after lesions of primate spinal cord. Brain Res. 58, 69-79. doi: 10.1016/0006-8993(73)90824-X

Vierck, C. J. Jr. (1974). Tactile movement detection and discrimination following dorsal column lesions in monkeys. Exp. Brain Res. 20, 331-346. doi 10.1007/BF00237379

Vierck, C. J. Jr. (1998). Impaired detection of repetitive stimulation following interruption of the dorsal spinal column in primates. Somatosens Mot. Res. 15, 157-163. doi: 10.1080/08990229870880

Vierck, C. J. Jr., and Cooper, B. Y. (1998). Cutaneous texture discrimination following transection of the dorsal spinal column in monkeys. Somatosens Mot. Res. 15, 309-315. doi: 10.1080/08990229870718

Wall, J. T., Xu, J., and Wang, X. (2002). Human brain plasticity: an emerging view of the multiple substrates and mechanisms that cause cortical changes and related sensory dysfunctions after injuries of sensory inputs from the body. Brain Res. Brain Res. Rev. 39, 181-215. doi: 10.1016/S0165-0173(02)00192-3

Wall, P. D. (1970). The sensory and motor role of impulses travelling in the dorsal columns towards cerebral cortex. Brain 93, 505-524. doi: 10.1093/brain/93.3.505

Wall, P. D. (1977). The presence of ineffective synapses and the circumstances which unmask them. Philos. Trans. R. Soc. Lond. B Biol. Sci. 278, 361-372. doi: 10.1098/rstb.1977.0048

Wang, Z., Qi, H. X., Kaas, J. H., Roe, A. W., and Chen, L. M. (2013). Functional signature of recovering cortex: dissociation of local field potentials and spiking activity in somatosensory cortices of spinal cord injured monkeys. Exp. Neurol. 249, 132-143. doi: 10.1016/j.expneurol.2013.08.013

Welker, W. I. (1973). Principles of organization of the ventrobasal complex in mammals. Brain Behav. Evol. 7, 253-336. doi: 10.1159/000124417

Wellman, C. L., Arnold, L. L., Garman, E. E., and Garraghty, P. E. (2002). Acute reductions in GABAA receptor binding in layer IV of adult primate somatosensory cortex after peripheral nerve injury. Brain Res. 954, 68-72. doi: 10.1016/S0006-8993(02)03343-7

Weng, H. R., Lenz, F. A., Vierck, C., and Dougherty, P. M. (2003). Physiological changes in primate somatosensory thalamus induced by deafferentation are dependent on the spinal funiculi that are sectioned and time following injury. Neuroscience 116, 1149-1160. doi: 10.1016/S0306-4522(02)00796-0

Willis, W. D., and Coggeshall, R. E. (2004). "Sensory pathways in the Dorsal Funiculus," in Sensory Mechanisms of the Spinal cord: Ascending Sensory
Tracts And Their Descending Control. $3^{\text {rd }}$ Edn, eds W. D. Willis and R. E. Coggeshall (New York, NY: Kluwer Academy/Plenum Publisher), 597-664. doi: 10.1007/978-1-4615-0035-3_9

Wise, S. P., Boussaoud, D., Johnson, P. B., and Caminiti, R. (1997). Premotor and parietal cortex: corticocortical connectivity and combinatorial computations. Annu. Rev. Neurosci. 20, 25-42. doi: 10.1146/annurev.neuro.20.1.25

Witham, C. L., and Baker, S. N. (2011). Modulation and transmission of peripheral inputs in monkey cuneate and external cuneate nuclei. J. Neurophysiol. 106 2764-2775. doi: 10.1152/jn.00449.2011

Wu, C. W., and Kaas, J. H. (1999). Reorganization in primary motor cortex of primates with long-standing therapeutic amputations. J. Neurosci. 19, 7679-7697.

Xerri, C. (2012). Plasticity of cortical maps: multiple triggers for adaptive reorganization following brain damage and spinal cord injury. Neuroscientist 18 , 133-148. doi: 10.1177/1073858410397894

Xu, J., and Wall, J. T. (1997). Rapid changes in brainstem maps of adult primates after peripheral injury. Brain Res. 774, 211-215. doi: 10.1016/S00068993(97)81706-4

Xu, J., and Wall, J. T. (1999). Evidence for brainstem and supra-brainstem contributions to rapid cortical plasticity in adult monkeys. J. Neurosci. 19, 7578-7590.

Yamahachi, H., Marik, S. A., McManus, J. N., Denk, W., and Gilbert, C. D. (2009) Rapid axonal sprouting and pruning accompany functional reorganization in primary visual cortex. Neuron 64, 719-729. doi: 10.1016/j.neuron.2009.11.026

Zhao, R. R., Andrews, M. R., Wang, D., Warren, P., Gullo, M., Schnell, L., et al. (2013). Combination treatment with anti-Nogo-A and chondroitinase ABC is more effective than single treatments at enhancing functional recovery after spinal cord injury. Eur. J. Neurosci. 38, 2946-2961. doi: 10.1111/ejn.12276

Zorner, B., Filli, L., Starkey, M. L., Gonzenbach, R., Kasper, H., Rothlisberger, M., et al. (2010). Profiling locomotor recovery: comprehensive quantification of impairments after CNS damage in rodents. Nat. Methods 7, 701-708. doi: 10.1038/nmeth.1484

Conflict of Interest Statement: The authors declare that the research was conducted in the absence of any commercial or financial relationships that could be construed as a potential conflict of interest.

Received: 06 March 2014; accepted: 22 April 2014; published online: 12 May 2014. Citation: Qi H-X, Kaas JH and Reed JL (2014) The reactivation of somatosensory cortex and behavioral recovery after sensory loss in mature primates. Front. Syst. Neurosci. 8:84. doi: 10.3389/fnsys.2014.00084

This article was submitted to the journal Frontiers in Systems Neuroscience.

Copyright (C) 2014 Qi, Kaas and Reed. This is an open-access article distributed under the terms of the Creative Commons Attribution License (CC BY). The use, distribution or reproduction in other forums is permitted, provided the original author(s) or licensor are credited and that the original publication in this journal is cited, in accordance with accepted academic practice. No use, distribution or reproduction is permitted which does not comply with these terms. 